\title{
CREDIT RISK AND RISK NEUTRAL DEFAULT PROBABILITIES: INFORMATION ABOUT RATING MIGRATIONS AND DEFAULTS
}

\author{
by \\ Gordon Delianedis and Robert Geske \\ The Anderson School at UCLA \\ May, 1998 \\ Current Version: May 1999
}

\begin{abstract}
Default probabilities are important to the credit markets. Changes in default probabilities may forecast credit rating migrations to other rating levels or to default. Such rating changes can affect the firm's cost of capital, credit spreads, bond returns, and the prices and hedge ratios of credit derivatives. While rating agencies such as Moodys and Standard \& Poors compute historical default frequencies, option models can also be used to calculate forward looking or expected default frequencies. In this paper, we compute risk neutral probabilities or default (RNPD) using the diffusion models of Merton (1974) and Geske (1977). It is shown that the Geske model produces a term structure of RNPD's, and the shape of this term structure may forecast impending credit events. Next, it is shown that these RNPD's serve as bounds to estimates of actual default probabilities. Furthermore, the RNPD's exhibit the same comparative statics as the estimates of actual default probabilities. Also, the risk neutral default probabilities may be more accurately estimated than actual default probabilities because they do not require an estimate of the firm's drift. Given these similarities and advantages of RNPD's, their estimates may possess significant information about credit events. To confirm this an event study of the relation between RNPD and rating migrations is conducted. We first show that these RNPD's from both the Merton and Geske models do possess significant and very early information about credit rating migrations. While the sample of firms that actually default during this time period is small, changes in the shape of the term structure of default probabilities appears to detect impending migrations to default. This is shown to be consistent with an inverted term structure of default probabilities, where prior to an impending default, the short term default probability is higher than the forward default probability. Finally, since rating migrations to either lower ratings or to default can be detected months in advance these credit events may not be a surprise.
\end{abstract}

We thank Jerry Bock, Teri Geske, Mark Grinblatt, Richard Roll, Avanidhar Subrahmanyam, Walt Torous, and two anonymous referees for their comments. The paper was presented at UCLA, the Bank of England, the WFA, and the AFA. Contact the authors by mail at The Anderson School at UCLA, 110 Westwood Plaza, Los Angeles, California 90095, USA, by telephone at 310-8253670 , by fax at 310-825-4528, or by e-mail rgeske@agsm.ucla.edu. 


\section{Introduction}

Fixed income markets are the largest capital markets in the world. In the United States, the fixed income markets are about two to three times as large as the equity markets. In most other countries, equity markets are even smaller relative to fixed income. Risks in fixed income (and other) markets are sometimes characterized as market risk and credit risk, although the two are not unrelated since changes in either risk are associated with security price changes. ${ }^{1}$ However, market risk is generally considered to be the risk associated with changes in prices of traded securities, usually bond prices, stock prices, foreign exchange prices, and commodity prices. Credit risk is the risk that the issuer of a fixed income security does not meet the security's promised obligations and thus defaults. For example, default could happen if the value of the issuer's assets falls below the value of the promised payments. Thus, credit risk is dynamic and is related to market risk because credit risk changes with variations in the value of the issuer's assets. While credit risk is important to all fixed income markets (including the sovereign risk of government bond markets), this paper is primarily concerned with corporate credit risk.

Today in most developed financial markets, derivative securities can be used to control the various forms of so-called market risk in a firm's balance sheet. For most firms, these balance sheet risks include equity risk, currency risk, interest rate risk, commodity price risk, and asset price risk. However, until recently few derivative securities were available to help hedge credit risk. This is now changing with the advent of credit derivatives, considered by some as the derivative market's new frontier. ${ }^{2}$ Default probabilities and changes in expected default frequencies are important to both the structure and pricing of credit derivatives.

Default is literally defined as failure to meet a required or contractual obligation. As noted, in financial markets this usually implies the corporate issuer failed to make a promised payment on its debt securities. When one considers the large number of corporations issuing fixed income securities and the relatively small number of actual defaults, one might regard default as a rare event. However, all corporate issuers have some positive probability of default. This default probability should change continuously with changes in the firm's stock price and thus its leverage. The value of most fixed income securities is typically inversely related to the probability of default. Investors are concerned about changes in the value of their fixed income securities due to changes in the probability of default, even though the actual default seldom occurs. In fact, fixed income investors may be more concerned with changes in the perceived credit quality of their bond holdings than with actual default. Rating migrations, which offer one reflection of changes in perceived quality of bonds, occur much more frequently than defaults. ${ }^{3}$

Rating agencies regularly measure the historical default frequency of both US and non US corporate issuers. While these historical default frequencies are interesting, they are not forwardlooking. Option models can provide a forward-looking, risk neutral default probability. Changes

\footnotetext{
${ }^{1}$ J.P. Morgan recently introduced Risk Metrics which deals with market risk and Credit Metrics which deals with credit risk. See www.jpmorgan.com for information about Risk Metrics and Credit Metrics.

${ }^{2}$ Blyth Masters of J.P.Morgan estimates the credit derivatives market to exceed $\$ 500$ billion dollars in notional. See her presentation at the Berkeley Program in Finance, (San Diego, September, 1997).

${ }^{3}$ In this study of approximately ten years (1986-1996) of US corporations rated by Standard and Poors on Compustat, the number of rating migrations (1650) was much greater than the number of migrations to default (13) after screening for sufficient CRSP and Compustat data..
} 
in this risk neutral default probability might provide leading information about changes in the credit quality of a debt issuer, and thus about either an impending rating change or default. ${ }^{4}$

From a theoretical perspective, default risk has been modeled in a variety of ways. Using diffusion processes to describe changes in the value of the firm, Merton (1974) was the first to demonstrate that a firm's default option could be modeled with the Black and Scholes (1973) methodology. He showed that stock could be considered as a call option on the firm with the strike price equal to the face value of a single payment debt issue. Geske $(1977,1979)$ extended Merton's analysis by showing that multiple default options for coupons, sinking funds, junior debt, safety covenants, or other payment obligations could be treated as compound options. ${ }^{5}$

The basic Merton model has been extended in many ways. Black and Cox (1977) allow for safety covenants, subordination arrangements, and limits on refinancing. Turnbull (1979) includes corporate taxes and bankruptcy costs. In order to study the interaction of default risk and interest rate risk, Kim, Ramaswamy, and Sundaresan (1993) allow the riskless interest rate to follow a square root process which is correlated with the firm value. They showed that default risk is not particularly sensitive to the volatility of interest rates but is sensitive to interest rate expectations. Longstaff and Schwartz (1995) also have stochastic interest rates correlated with the firm process, an exogenous early default and an exogenous recovery rate. Leland (1995) endogenizes the bankruptcy decision while accounting for taxes and bankruptcy costs.

Altman $(1977,1986)$ took a different approach using z-scores and discriminant analysis to examine risky corporate debt. Another approach has been to model default as a rare event, or Poisson process. Mason and Bhattachayra (1981) allowed the firm to follow a discontinuous Poisson process with more complex boundary conditions. Jarrow and Turnbull (1995) model default as a Poisson event when pricing derivatives with credit risk . Duffie and Singleton (1997), when considering the term structure of defaultable bonds or swaps, model the default event as an inaccessible stopping time, such as a Poisson arrival. They argue that this is appropriate because when defaults do occur, they are rarely anticipated even a short time before the event. However, here we show that this is not necessarily the case.

The focus of this research is the properties of risk neutral default probabilities, especially their estimation, their size as an upperbound on actual default probabilities, their sensitivities, their term structure, and the information embedded within them about credit risk. The market has an interest in estimates and properties of default probabilities, both actual and risk neutral, in order to learn more about credit risk. We could also focus on default spreads from option models or on converting risk neutral default probabilities to actual default probabilities, but those topics are left for future research.

In this paper we use the option models of Merton (1974) and Geske (1977) to estimate a monthly time series of risk neutral default probabilities over approximately 10 years, from 1987 to 1996. We then examine the changes in these default probabilities before the event of a rating

\footnotetext{
${ }^{4}$ While risk neutral default probabilities are germane for pricing and hedging, it remains to be seen how relevant they are for estimating actual default frequencies and for use in, for example, value at risk (VAR).

${ }^{5}$ Both the Merton and Geske models can be generalized to incorporate stochastic interest rates (Merton (1973)), stochastic payouts (Geske (1978)) and thus stochastic recovery, and the first passage to a solvency boundary using the method Geske and Johnson (1984) used to value American put options.
} 
migration or default. There appears to be significant leading information about rating migrations and about defaults in these forward looking risk neutral probabilities of default. The term structure of default probabilities from the Geske model appears to contain additional information. The short term probability of default from the Geske model appears to contain significant information about both the default event and the shape of the term structure of default probabilities prior to the actual default. It appears this short term default probability is able to distinguish impending cash flow problems for the firm.

Furthermore, rating migrations and defaults do not appear to be a surprise to the market since they can be detected months in advance by either model. Thus, the diffusion approach to credit migrations and default may be as, or more, appropriate than the Poisson approach.

In section 2 of the paper we present a brief description of the models and the derivations of each model's risk neutral default probabilities. Section 3 describes our data sources and construction, section 4 presents our results, and section 5 offers some conclusions. 


\section{The Models}

Here we assume that investors are both greedy and risk averse when they value the firm, while investors only need to be greedy when they value the stock and bonds as options on the firm. We make this assumption so that the drift of the firm, which is not necessary for pricing the options, will exceed the risk free rate in order to avoid arbitrage when pricing the firm.

\subsection{Merton Model}

Merton modeled the option to default by considering the stock in a leveraged firm as a call option on the assets of the firm with an exercise price equal to the face value of the total debt obligations. If the firm's liabilities are approximated as simply a single issue of pure discount debt with face value $\mathrm{M}$ maturing at date $\mathrm{T}$, then the boundary condition for the stock at date $\mathrm{T}$ is $S_{T}=\max \left(0, V_{T}-M\right)$. This boundary condition is identical to the boundary condition for a call option. Thus, if the firm's behavior is assumed to be the same as Black-Scholes assumed for pricing options on stock, then the stock can be priced as a call option on the firm. The solution for the current stock price subject to this boundary condition is the well-known Black-Scholes equation:

$$
S=V N_{1}\left(k+\sigma_{v} \sqrt{T-t}\right)-M e^{-r_{F}(T-t)} N_{1}(k)
$$

where

$$
k=\frac{\ln (V / M)+\left(r_{F}-1 / 2 \sigma_{v}{ }^{2}\right)(T-t)}{\sigma_{v} \sqrt{T-t}},
$$

and

$\mathrm{S} \quad=$ current market value of the stock,

$\mathrm{V} \quad=$ current market value of the firm,

$\mathrm{M} \quad$ = face value of the debt,

$r_{F} \quad=$ the risk-free rate of interest,

$\sigma_{v} \quad=$ the instantaneous variance of the return on the firm's assets,

$\mathrm{t} \quad=$ current time,

$\mathrm{T}=$ maturity date of the debt,

$N_{1}()=$. univariate cumulative normal distribution function.

In this model, the risk neutral probability held today that the value of the firm will be greater than the face value of the debt at the future date $\mathrm{T}$, or $V_{T} \geq M$, is $N_{1}(k)$. Thus the risk neutral probability that the firm will be insolvent ${ }^{6}$ and default $\left(\operatorname{RNPD}_{\mathrm{M}}\right)$ on its debt obligation at date $\mathrm{T}$ for the Merton model is:

$$
R N P D_{M}=1-N_{1}(k)
$$

\footnotetext{
${ }^{6}$ In this simple model default and insolvency are equivalent. Also, in this paper we do not consider the effects of payouts, either coupons or dividends. In another paper concerned with converting risk neutral probabilities to actual default frequencies we do examine the effects of these payouts on the probability estimation.
} 
This risk neutral default probability is forward-looking and might be considered an "expected" default frequency conditional on the firm's current value, leverage, volatility, debt structure, and the market risk-free interest rate. ${ }^{7}$ If a firm has a more complex liability structure on its balance sheet than simply one issue of pure discount bonds, then the Merton model does not directly apply. However, with some loss of generality in the Merton model, a single liability can be constructed by repositioning the value of the firm's multiple liabilities to the duration of those liabilities. Alternatively, one might consider the actual multiple liabilities using Geske's compound option approach described in the next section.

\subsection{Geske Model}

Geske (1979) generalized the Black-Scholes option pricing model by using Merton's framework that if stock is an option on the asset's of the firm, then an option on stock is an option on an option, or a compound option. Geske (1977) also extended Merton's simple balance sheet of one pure discount bond and only one option to default by allowing for multiple options to default on short term debt, junior or subordinated debt, coupon payments, amortizing debt, sinking funds, safety covenants, and other possible promised or restricted payments.

Consider a firm that has both long term and short term debt. Assume that the long term debt, $M_{2}$, matures at date $T_{2}$, and the short term debt, $M_{1}$, matures at date $T_{1}$, where $T_{2} \geq T_{1}$. If at date $\mathrm{T}_{1}$ the value of the firm, $V_{T_{1}}$, is greater than the face value of the short term debt, $\mathrm{M}_{1}$, plus the market value of the long term debt at $\mathrm{T}_{1}, B_{2 T_{1}}$, then the firm is not bankrupt and can refinance. This is equivalent to the statement that the value of the stock at date $T_{1}$, after paying off the short term debt, $\mathrm{M}_{1}$, is positive. ${ }^{8}$ Thus, there is a critical value of the firm at date $\mathrm{T}_{1}, \bar{V}_{T_{1}}$, that satisfies the following equation:

$$
V_{T_{1}}=M_{1}+B_{2_{T_{1}}}=M_{1}+V_{T_{1}}-S_{T_{1}}=M_{1}+V_{T_{1}}-V_{T_{1}} N\left(k_{2}+\sigma_{v} \sqrt{T_{2}-T_{1}}\right)+M_{2} e^{-r_{F 1}\left(T_{2}-T_{1}\right)} N\left(k_{2}\right)
$$

A refinancing assumption is reasonable because firms generally do not pay off their short term debt without refinancing since that would dramatically shrink the value of the firm and increase the probability of default on the remaining debt. Furthermore, this refinancing condition has the additional realism that it forces the firm to cross default on all its debt at once if it is insolvent. ${ }^{9}$

Thus substituting the solution for the terminal boundary problem into the intermediate boundary condition and solving for the value of the stock today yields the following equation:

$$
S=V N_{2}\left(k_{1}+\sigma_{v} \sqrt{T_{1}-t}, k_{2}+\sigma_{v} \sqrt{T_{2}-t} ; \rho\right)-M_{2} e^{-r_{F 2}\left(T_{2}-t\right)} N_{2}\left(k_{1}, k_{2} ; \rho\right)-M_{1} e^{-r_{F 1}\left(T_{1}-t\right)} N\left(k_{1}\right)
$$

\footnotetext{
${ }^{7}$ Here we sometimes refer to risk neutral default probabilities as expected default frequencies since they may forecast actual default frequencies. A similar concept is discussed in KMV's Credit Monitor Overview.

${ }^{8}$ The value of the stock at $T_{1}$ after paying off $M_{1}$ is given by equation (1). Instead, either no refinancing or refinancing with short and long term debt could be modeled, but evaluation would generally require numerical analysis. Refinancing keeps the firm process continuous. See Geske (1977) and Black and Cox (1976).

${ }^{9}$ Also, the Geske model need not collapse to the Merton model even when there is no short term debt $\mathbf{M}_{1}$ paid out and refinanced at $T_{1}$ if there still remains a solvency condition on the value of the firm at $\mathrm{T}_{1}$. See Black and Cox (1976), p. 362, and Geske (1977) for further discussion.
} 
where, with the notation given above, plus $\rho=\sqrt{\left(T_{1}-t\right) /\left(T_{2}-t\right)}$, and $\mathrm{N}_{2}($ ) is a bivariate cumulative normal distribution function with the following integral limits:

$$
\begin{aligned}
& k_{1}=\frac{\ln (V / \bar{V})+\left(r_{F 1}-\frac{1}{2} \sigma_{v}^{2}\right)\left(T_{1}-t\right)}{\sigma_{v} \sqrt{T_{1}-t}} \\
& k_{2}=\frac{\ln \left(V / M_{2}\right)+\left(r_{F 2}-\frac{1}{2} \sigma_{v}^{2}\right)\left(T_{2}-t\right)}{\sigma_{v} \sqrt{\left(T_{2}-t\right)}} .
\end{aligned}
$$

Since Merton (1973) has solved the option pricing problem when the term structure of interest rates is stochastic, we could examine the risk structure with a stochastic term structure. Equations (1) and (5) would be the same except we would replace the discount factors by riskless discount bonds that pay one dollar at the appropriate date in the future and replace the firm variance with a generalized variance which includes the variance of the interest rates and the covariance between the interest rates and the firm.

In this simple version of the Geske model there are two options to default. Thus the following risk neutral probabilities of default can be computed: (1) the Total or joint probability of defaulting at either date $\mathrm{T}_{1}$ or date $\mathrm{T}_{2}$; (2) the Short probability of only defaulting on the short term debt at date $\mathrm{T}_{1}$; and (3) the Forward probability held today of defaulting on the long term debt at date $\mathrm{T}_{2}$, conditional on not defaulting on the short term debt at date $\mathrm{T}_{1}$. The Total probability ${ }^{10}$ of defaulting at both date $\mathrm{T}_{1}$ or date $\mathrm{T}_{2}$ is:

$$
R N P D_{T_{T}}=1-N_{2}\left(k_{1}, k_{2} ; \rho\right) .
$$

The Short probability of defaulting on the short term debt at date $\mathrm{T}_{1}$ is:

$$
R N P D_{G_{S}}=1-N\left(k_{1}\right) .
$$

The Forward probability of defaulting on the long term debt at date $T_{2}$, conditional on not defaulting on the short term debt at date $\mathrm{T}_{1}$, is:

$$
R N P D_{G_{F}}=1-\frac{N_{2}\left(k_{1}, k_{2} ; \rho\right)}{N\left(k_{1}\right)} .
$$

Thus, this simple version of the compound option approach to the balance sheet provides a term structure of default probabilities which includes a Short, Total and Forward risk neutral default probability. More generally, with more than two default opportunities, the Geske model

\footnotetext{
${ }^{10}$ This is a bivariate or joint probability of either not being able to refinance at $T_{1}$, or refinancing at $T_{1}$ but not being able to payoff the long term debt at $\mathrm{T}_{2}$. This bivariate probability can be easily evaluated numerically.
} 
can provide a more complete term structure of spot and forward default probabilities. However, this simple version may capture some of the short term cash flow problems created by fluctuations in current liabilities and other short term debt, which we show constitute a significant portion of many firms' debt obligations.

\subsection{Model Implementation}

As the debt maturity $\mathrm{T}$ increases, the Merton risk neutral default probability will converge in the limit to either 0 or 1 , depending on whether the interest rate, $r_{T}$, is greater or less than $1 / 2 \sigma_{V}{ }^{2}$, respectively. The Geske Total default probability will not converge to 0 or 1 as the long term debt maturity increases because of the positive probability of defaulting on the short term debt.

Both the Merton equation (1) and the Geske equation (5) for the stock price contain the same two unknowns ${ }^{11}, \mathrm{~V}$ and $\sigma_{v}$. In addition, the Geske model requires $\bar{V}_{T_{1}}$, which can be found directly by solving equation (4). To solve for $\mathrm{V}$ and $\sigma_{v}$ in both models, we need the following well-known additional equation relating the volatility of an option to the volatility of the underlying asset:

$$
\sigma_{s}=\frac{\partial S}{\partial V} \frac{V}{S} \sigma_{v}
$$

Given data on the firm's stock price, the number of shares outstanding, the face value and maturity of the liabilities, and the term structure of interest rates, we can solve both Merton and Geske models for $\mathrm{V}, \sigma_{v}$, and $\bar{V}_{T_{1}}$. The solution to both models requires a numerical algorithm to search for the parameters such that equations (1) and (11) for the Merton model, and equations (4), (5) and (11) for the Geske model are satisfied.

\subsection{Risk Neutral Preferences, Probabilities, and Term Structures of Default Probabilities}

Risk neutral default probabilities are closely tied to the actual default probabilities because they serve as an upper bound, they have the same sensitivities, and they may be more accurately estimated. To understand this recall the risk neutral argument of Cox and Ross (1976) provides an original alternative to solving derivative valuation problems. Instead of formulating the problem as solving a partial differential equation, they formulated it as solving an integral equation. Their main idea was if utility preferences and the expected return on the underlying asset are not relevant for solving the derivative pricing problem, then any set of preferences and a consistent drift would work. They showed that the problem was simplified by assuming risk neutral preferences and thus a drift for the underlying asset equal to the risk free rate. However, the actual variance of the underlying asset would still be relevant for pricing derivatives regardless of the drift.

\footnotetext{
${ }^{11}$ The actual estimation will produce different values for $\mathrm{V}$ and $\sigma_{v}$ depending on the model used.
} 
The risk neutral argument offers not only an alternative valuation approach, but also provides a deeper understanding of option models. The "probabilities" in the Black-Scholes formula do not represent the actual probability of being above or below the strike price at expiration. Since the underlying asset is risky it does not actually drift at the risk free rate. At any terminal boundary the center or mean of this risk neutral terminal distribution will not be the mean of the actual distribution, even though the variance of the risk neutral distribution is the variance of the actual distribution. The probability of being above or below any exercise boundary at expiration is termed a "risk neutral probability" because the underlying asset is assumed to drift at the risk free rate. In order to convert these risk neutral probabilities to actual probabilities, the expected return of the underlying asset must be estimated. However, it is well known that expected returns on equities are estimated with significant error. Because risk neutral probabilities of default (RNPD) can be calculated without estimating the firm's expected return, RNPD may be more accurately estimated than actual default probabilities.

Also, the RNPD will generally serve as an upper bound to the actual probability of default (APD). Option pricing theory requires investors to be greedy, but not necessarily risk averse. Thus, the underlying asset can be overpriced, underpriced, or fairly priced and still be consistent with the option approach. However, for the purpose of this paper we make the more usual and stronger assumption for pricing non-derivative assets (such as the firm) that investors are risk averse. Thus, the expected return on the firm must exceed the risk free rate to avoid arbitrage. Then, it follows immediately, given two lognormal terminal distributions fully characterized by the first two moments, if the variances are the same, then for any required payment at maturity, the distribution with the smaller mean will have the higher default probability. Since the actual and risk neutral distributions of the firm have the same variance and the actual distribution must have a mean greater than the risk free rate, then the risk neutral distribution will have the larger default probability. The actual and risk neutral default probabilities will be equal only if the underlying asset is expected to grow at exactly the risk free rate. Thus, we have the following inequality:

$$
R N P D \geq A P D
$$

Finally, the RNPD and the APD will have the same sensitivities to the variables which effect the option value. Thus, both measures of the default probability will be increasing in the face value of debt and the volatility of the firm's assets, will be decreasing in the value of the firm and the risk free interest rate, and can be increasing or decreasing in the maturity of the debt. ${ }^{12}$

The term structure of default probabilities could be interesting for examining the changing credit structure of either individual firms, industries, or the whole economy. Thus, a term structure of default probabilities could contain information about the business cycle. A default term structure will contain both unconditional and conditional probabilities of default where the conditioning is on having or not having previously defaulted. Also, forward default probabilities contain information about credit arbitrage, and a negative forward default probability would imply a credit arbitrage opportunity.

\footnotetext{
${ }^{12}$ Here we assume that the firm's risk premium is independent of the risk free rate, and thus if the risk free rate increases, the expected return on the firm must increase. However, the actual default probability will be decreasing in the expected return on the firm, while the risk neutral default probability is independent of this expected return.
} 
Typically, the term structure of unconditional default probabilities should be upward sloping because the probability of default over a specific time horizon increases with time. ${ }^{13}$ However, the term structure of default probabilities would be inverted when the Short term default probability is greater than the Forward default probability. This may occur whenever the firm has a high probability of defaulting in the short term, but if it can survive through the next year and payoff its short term obligations, then the firm's default probability might decline. In this situation, the Forward default probability would be less than the Short term default probability. For example, using equations (8), (9), and (10), a firm with a Total default probability of 0.6 and a Short term default probability of 0.5 , would have a Forward default probability of 0.2 .

The next section describes the sources and construction of the data necessary to estimate the risk neutral default probabilities.

\footnotetext{
${ }^{13}$ While the slope of the unconditional default probability term structure should be positive, the slope of the conditional default probabilities (for example, one year conditional), holding credit rating and risk constant, could be positive, zero, or negative. However, allowing the credit rating (risk) to increase (decrease), then the forward conditional default probabilities could decrease.
} 


\section{The Data}

\subsection{The Data Sources and Organization}

The three sources of data used in this paper are Compustat, CRSP, and DRI. The Compustat database provides quarterly observations of each firm's capital structure and Standard and Poor's ratings. The Center for Research in Security Prices, (CRSP) data base provides the daily stock price data. Data Resources Incorporated, (DRI), provides monthly data on the term structure of interest rates

Every quarter for the past 12 years, the quarterly Compustat tapes report the Standard \& Poors (S\&P) rating for a representative issue of a company's debt. We use this composite rating as a proxy for the rating of all of the company debt. ${ }^{14}$ The S\&P rating system is comprised of 27 categories, where the first represents non-rated (NR) firms, and the next 26 represent credit levels from highest "AAA" to the lowest default, "D". We assign an integer value to each rating class from a 2 (AAA) down to a 27 (D). The credit event of interest is changes in a firm's credit rating which are measured by the numerical difference between the rating before and after the event date. The resulting rating changes will all be integer values. However, with quarterly rating data the event date is actually a three month event window, and we do not know exactly when the rating change occurs within a quarter.

First we collect every firm that has a valid non-default rating and use this as our market baseline sample. $^{15}$ Next we collect all the firms that have experienced a rating change between any two adjacent quarters and use this as our event sample. This includes firms that have changed ratings to default, but not firms that change rating to or from "not available or NA" 16 or firms which change rating from default. For firms that change credit rating, we collect a time series of data starting 8 quarters ( 24 months) prior to the event and extending through the quarter of the event. This provides a total of 9 quarterly observations for each firm. .

The other Compustat data items required are the firms' liability structure and maturity. Here we use the annual Compustat tapes to determine the maturity of the liabilities and then apply these maturities to the quarterly observations of the firms liabilities. This way we get quarterly updates of the balance sheet while getting a finer measure of the liabilities maturity. The annual Compustat tape divides total liabilities into current liabilities, debt due in years 1,2,3,4, and 5, long term debt, deferred taxes, minority interest, and other long term liabilities. We assume that the maturity of current liabilities is 6 months and that the maturity of all other liabilities as 10 years unless explicitly stated, as is the case for debt due in 1,2,3,4,and 5 years. Additionally, in order not to overstate short term debt, we reduce accounts payable by the liquid current assets of cash, marketable securities, and accounts receivable.

Then, for the Merton model, which allows only one liability maturity, we use Macaulay duration to reposition the face value of the firm's multiple liabilities to a single duration for all the liabilities. For the Geske model, we designate current liabilities and debt due in one year as short term liabilities, and total liabilities minus short term liabilities as long term liabilities. We then

\footnotetext{
${ }^{14}$ Hite and Warga (1997) also find that using one representative rating per company may be sufficient given the cross default provisions in most corporate debt.

${ }^{15}$ In this study we examine firms that move into default, but not firms that move out of default.

16 This is a small number of firms, but may cause a slight bias if distressed firms are not rated.
} 
compute the duration for both the short term liabilities, $\mathrm{T}_{1}$, and the long term liabilities, $\mathrm{T}_{2}$. The face values are then taken from the quarterly Compustat tapes. The short term liability, $\mathbf{M}_{1}$, is equal to the current liabilities plus the debt due in 1 year, and the long term liabilities is equal to the total liabilities less the short term liability, both with the netting of accounts payable.

During the period 1987-1996, we use DRI for interest rates to obtain an appropriate time series of discount factors from government bills, notes, and bonds corresponding to each Compustat debt maturity during each month over the entire sample. ${ }^{17}$

For each quarterly Compustat observation, we collect from CRSP the stock price and shares outstanding for the month beginning that quarter and for two subsequent months. We also calculate the stock volatility over the previous 60 trading days prior to each monthly observation. Thus, the CRSP daily frequency of stock price changes allows us to construct a monthly time series of the firm's value, volatility, and leverage changes, assuming that the firm's debt obligations and rating does not change during the quarter.

Given the monthly stock price and estimated stock volatility (CRSP), the relevant face value and duration of each firm's balance sheet (Compustat), and the relevant interest rate (DRI), we can solve equations (1) and (11) for the Merton model's estimate of $V_{M}$ and $\sigma_{V_{M}}$ and equations (4), (5), and (11) for the Geske model's estimates of $\bar{V}_{T_{1}}, V_{G}$ and $\sigma_{v_{G}}$.

Next, a monthly time series of RNPD from both models is computed for all Compustat firms rated by Standard and Poors. For each quarterly observation, 3 RNPD are computed using the monthly stock and volatility data. While the number of firms in our sample ranges from 597 in 1987 to 947 in 1996, on average there are 668 firms each year. Since there are 120 months and on average 668 firms, we compute over 80,000 RNPD for the Merton model and over 240,000 RNPD for the Geske model.

Hereafter, the Merton and Geske models are referred to as the $M$ and $G$ models, respectively. In the next section we discuss the firm credit data in more detail.

\subsection{Firm Credit Data: Credit Classes, Rating Migrations, and Migration Magnitudes}

In this section we examine the Standard and Poors' rating classes and rating migrations during the period 1986-1996. We also present and compare leverage ratios, firm volatility, and risk neutral default probabilities for both the $\mathrm{M}$ and $\mathrm{G}$ models during this time period.

Table 1, Panel A, shows the number of firms in each rating category from AAA to $\mathrm{B}^{18}$, while Panel B shows the percent of the total sample that each rating category comprises, for the years 1986 through 1996. For example, during this time period the percent of firms rated either AAA, AA, or A dropped from $44.8 \%$ of the sample in 1986 to $33.8 \%$ in 1996, while the firms rated either $\mathrm{BBB}, \mathrm{BB}$, or $\mathrm{B}$ rose from $55.2 \%$ of the sample in 1986 to $66.2 \%$ in 1996 . This is

\footnotetext{
${ }^{17}$ Since there is no 4 year note, we use an average of the 3 and 5 year note for the 4 year rate.

18 The B category includes all firms rated B or below.
} 
consistent with the notion that the average quality as measured by ratings of US Corporate issuers has declined during this period. ${ }^{19}$

Table 2, Panel A reports the number of credit migrations by rating and by year, and Panel $B$ reports the number of rating changes by magnitude and by year, where "+" denotes an upgrade, "-" denotes a downgrade, IG denotes investment grade (classes AAA, AA, A, BBB), and NIG denotes non-investment grade (BB, B and below). Panel A again support the idea that credit quality as measured by Standard and Poors' rating has declined during the period 1986-1996, since there have been 19\% more downgrades (895) than upgrades (752).

Table 2, Panel B reports the number of credit migrations by magnitude and by year. We report this because if the market has information about an impending rating change, then there may be more information in large rating changes. For example, a change of +1 could indicate a migration from $\mathrm{B}$ - to $\mathrm{B}$, while a change of -3 could indicate a migration from AA to $\mathrm{A}$. Changes greater than -3 could be from AA to A-, but it could also be from AA- to D. While large magnitude rating changes (greater than $+/-3$ classes) do not occur very frequently in our sample (less than 10 per year either up or down in all years but one), large downgrades of magnitude -3 or more (total 130) occur about 3 times more frequently than large upgrades of magnitude +3 or more (total 50). ${ }^{20}$

The investment grade classes exhibit substantially more downgrades (581) than upgrades (363), while the non-investment grade classes exhibit slightly more upgrades (389) than downgrades (314). Furthermore, the investment grade classes show more than three times as many quasi-large downgrades (194 greater than -1) than quasi-large upgrades (63 greater than +1$)$, while these same magnitude changes are more balanced for the non-investment grade firms (133 up $>1 ; 136$ down $<-1)$.

These first two tables indicate that if there is more information in larger rating migrations, then since downward migrations exhibit more large changes than upward migrations, research may find both more statistical and economic significance in the downgrade sample. ${ }^{21}$

Tables 1 and 2 show that the number and percent of AAA and AA firms is small relative to the other rating classes, and also that their number of rating migrations is very small relative to the other classes. Thus, it may make sense to examine the larger samples of investment grade and non-investment grade firms. ${ }^{22}$

Table 3 has three panels of information about the investment grade and non-investment grade firms. Panel A presents the event transition rate, which is the percentage of investment grade and non-investment grade firms out of the total sample that migrated up or down. For example, for investment grade firms, on average $8 \%$ per year migrate up and $12 \%$ migrate down, while for non-investment grade firms, on average about $16 \%$ per year migrate up and $13 \%$ migrate down. Thus, non-investment grade firms exhibit about twice the rate of migration (39\%) (either

\footnotetext{
${ }^{19}$ Blume, Lim, and MacKinlay (1997) also find this result in their data and question whether this decline in quality is myth or reality.

${ }^{20}$ Since no AAA- class exists, a downgrade from AAA to AA+ represents a -2 magnitude change.

${ }^{21}$ Hite and Warga (1997) study of bond rating changes and bond price performance supports this notion.

${ }^{22}$ Rating migrations between IG and NIG may contain more information since that particular rating change alters the composition of possible buyers because some investors are restricted to holding only IG credits.
} 
up or down) as investment grade firms (20\%). Also, as might be expected, investment grade firms are more likely to migrate down while non-investment grade firms are more likely to migrate up.

Table 3, Panel A, also has the magnitude weighted event transition rate. This number weights each up and down migration by the size of the change. This magnitude weighted transition rate shows that on average the non-investment grade firms have not only more frequent but also larger rating changes than the investment grade firms. This data also indicates that the magnitude weighted transition rates are about equal for up (0.243) and down (0.244) rating changes for the non-investment grade firms, while the investment grade firms have much larger magnitude weighted transition rates for downward moves (0.182) than for upward moves (0.097).

Table 3, Panel B illustrates the median theoretical debt to firm value and implied firm volatility for the M and G models for the years 1987 through 1996 for the entire baseline sample. As might be expected, we see that both models indicate non-investment grade firms have more leverage than investment grade firms. Both the $\mathrm{M}$ and $\mathrm{G}$ models indicate investment grade firms have on average about $33 \%$ leverage during this period, while non-investment grade firms have on average $45 \%$ and $49 \%$ leverage, respectively. The $\mathrm{M}$ and $\mathrm{G}$ models have the same average theoretical annual firm volatility of 0.17 for investment grade firms this decade. ${ }^{23}$ For noninvestment grade firms the $\mathrm{M}$ and $\mathrm{G}$ models annual firm volatility is 0.274 and 0.234 , respectively, suggesting that non-investment grade firms exhibited on average about 45-55\% more expected volatility than investment grade firms during the time period 1987-1996. Both models also indicate that investment grade and non-investment grade firms had the highest expected or implied volatility the year of the stock market crash, and the lowest implied volatility during the years preceding the 1990-1991 Bush recession.

The median risk neutral probabilities of default (RNPD) for the period 1987 through 1996 are shown in Panel $\mathrm{C}$ of Table 3. As described in section 2, the $\mathrm{G}$ model produces a term structure of default probabilities, here labeled the Total, the Short, and the Forward RNPD, while the M model produces just one RNDP. Recall that the three G model probabilities represent the Total probability of defaulting on both the short term and on the long term obligations, the Short probability of defaulting only on the short term obligation, and the Forward conditional probability of defaulting on the long term obligations if the firm does not default on the short term debt.

First note that the average median risk neutral default probabilities over the decade 19871996 for the $\mathrm{M}$ and $\mathrm{G}$ models for investment grade firms is $2.1 \%$ and $1.0 \%$, respectively, while for non-investment grade firms this same comparison of the $\mathrm{M}$ and $\mathrm{G}$ models reveals $22.6 \%$ and $10.9 \%$, respectively. Thus, during this time period the $\mathrm{M}$ model exhibits higher risk neutral default probabilities than the $G$ model. This difference arises primarily from three sources: 1) given the known variables, the solutions to the $\mathrm{M}$ and $\mathrm{G}$ models for the unknown firm value and volatility are different; 2) the G model considers two debt obligations and refinances the short

\footnotetext{
${ }^{23}$ This average firm volatility may seem high compared to the average volatility of the S\&P 500 stock portfolio, but that comparison is not valid. The average volatility of the S\&P reflects diversification, while this is simply a weighted average of each firm volatility.
} 
term debt with equity, while the $\mathrm{M}$ model has only one debt obligation; and 3) both models' risk neutral default probabilities are sensitive to the treatment of short term assets and liabilities. ${ }^{24}$

Also note that both the $\mathrm{M}$ and $\mathrm{G}$ models indicate that the year of the stock market crash exhibited the highest risk neutral default probability for both the investment grade firms $(10.5 \%$ and $7.2 \%$, respectively) and the non-investment grade firms (29.6\% and $20.5 \%$, respectively). However, for non-investment grade firms the G model's Short RNDP indicates that the expected defaults over the next 6-12 months was as high during and immediately after the "Bush" recession of 1990-1991 as during the year of the crash (0.006).

For the baseline sample of firms, the term structure of risk neutral default probabilities from the $\mathrm{G}$ model is upward sloping on average for both investment grade and non-investment grade firms during the period 1987-1996. This can be seen by comparing the G Short RNPD to the Forward RNPD. This default probability term structure appears to be the steepest for both investment grade and non-investment grade firms in 1987, while it appears to be the least steep in 1989.

Figure 1 illustrates graphically both the levels and the differences in the risk neutral default probabilities during this decade for the entire baseline sample of firms. For both models, the highest risk neutral default probabilities are reached after the stock market $\mathrm{crash}^{25}$ and during and after the Bush recession for all firms. The G model's Short term default probabilities are generally much less than the other default probabilities. In a later table it is shown that this is not the always the case for specific firms a few months prior to actual default.

\footnotetext{
${ }^{24}$ In another paper (1998) we analyze these sensitivities in detail, compare the risk neutral default probabilities to Moody's actual default frequencies, and discuss the default risk premium.

${ }^{25}$ There is some induced persistence in the monthly firm volatility since the monthly stock volatility is computed using the previous 60 daily stock returns.
} 


\section{Results From Risk Neutral Default Probabilities}

\subsection{Information in Risk Neutral Default Probabilities about Rating Migrations}

Here we investigate the changes in the time series of risk neutral default probabilities before a credit migration. If the market is efficient and the model is able to extract the market information, then the risk neutral probabilities of default from the option model may reveal the increasing or decreasing credit risk prior to the actual change in the Standard and Poors rating.

Therefore, we examine and report the median default probabilities ("Raw") for investment grade and non-investment grade firms 24 months before the event. It is thought that those firms that are downgraded (upgraded) will exhibit an increase (decrease) in the risk neutral default probability before the event, when measured relative to other firms of the same rating that do not change rating category.

\subsubsection{Graphs}

Figure 2a illustrates the event study graphically for the sample of all rating downgrades, for both investment grade firms and non-investment grade firms, and for both the $\mathrm{M}$ and $\mathrm{G}$ models. In the top graph, the investment grade firms Raw M model RNPD appears to move up and away from the baseline RNPD at about 12 months prior to the downgrade event. This indicates these firms exhibit increasing credit risk as measured by the risk neutral probability of default prior to actually being downgraded.

Recall that the baseline is the median risk neutral default probability for a matched sample of firms with the same contemporaneous rating. At the event window, when each downgraded firm receives a new rating category, if this firm is to be compared to firm's with similar ratings, then the base rating must also change to the new average rating of the re-rated firms. Thus, after the event window the difference between the Raw and Base RNPD should approach zero. The persistence of a difference may indicate that the actual rating change did not fully reflect the market's future expectations, or a difference in rating methodologies..

Figure 2a shows that the $\mathrm{G}$ model also exhibits noticeable differences between the Raw and the Base RNPD months prior to the event for the Total, Short and Forward RNPD's. Furthermore, for both models, significant differences between the Raw and the Base RNPD seem to appear earlier for the non-investment grade firms when compared to the investment grade firms.

Figure $2 \mathrm{~b}$ illustrates graphically these same risk neutral probabilities of default for both the $\mathrm{M}$ and $\mathrm{G}$ models for all rating upgrades. Here, if the market is efficient and the models can reveal the market information, we would expect the Raw RNPD for the upgraded firms to decrease below the Base RNPD prior to the upgrade event. It appears that both the M and G models reveal information about the impending upgrade, in some instances perhaps 24 months prior to the upgrade event. However, the graph of the G model's Short RNPD does not appear to contain significant information for the investment grade firms. This is probably because the investment grade firms (AAA-BBB) are already difficult to distinguish because of their low default probabilities, and an upgrade implies a further reduction in this probability. 
We conjecture that the magnitude of a rating change may reflect the amount of information about the credit worthiness of a corporation and the dollar value of the corporation's debt. Thus, perhaps a larger upgrade or downgrade event would contain more information. Thus, Figures $2 \mathrm{c}$ and $2 \mathrm{~d}$ illustrate rating changes of 2 or more rating categories, up or down. Figure $2 \mathrm{c}$ does appear to illustrate that the market and model are able to detect the larger downgrade events earlier for both investment grade and non-investment grade firms, with both the $\mathrm{M}$ and $\mathrm{G}$ models. However, for the larger upgrade event, Figure $2 \mathrm{~d}$ seems to indicate that while there is noticeable early information in the RNPD, it does not appear to be as strong or consistent as in the sample of upgrades of 1 or more rating categories.

\subsubsection{Tables and Statistics}

The statistical tests are based on whether our event sample differs significantly from the baseline sample. Since the RNPD's are not normally distributed and are skewed, we adjust the event sample with the median of the baseline instead of the mean. Thus, we take the monthly differences between the "Raw", or unadjusted RNPD, of the firms that will migrate and the contemporaneous median of the larger baseline sample of all firms in the same rating class, which includes those that migrate and those that do not migrate. The median of these differences are called the adjusted RNPD and labeled "Med". Then, on these differences we report the following statistics, the percent positive $(\%+)$ for upgrades and the percent negative for downgrades (\%-), and a non-parametric sign test (p-value) on Med, and the number of firms each month. The sample sizes vary based on data availability, conditional sampling, and parameter convergence.

Table 4 is a summary page of statistics for the sample of all downgrades using the $\mathrm{M}$ model. The table covers both investment grade and non-investment grade firms and the conditional and unconditional samples. This table is one of 16 such possible tables representing all combinations of event magnitudes (all or rating changes of more than 1 rating category), migration direction (up or down), and model selection ( $\mathrm{M}$ or $\mathrm{G}$-short, total, forward). The data is presented for 2 years or 24 months prior to the event quarter and through the 3 month event window

The sample sizes are large, ranging between 413 and 563 investment grade firms, and 192 to 297 non-investment grade firms. Some of these firms experience more than one downgrade prior to the event date. These firms with multiple downgrades may experience more dramatic changes in their RNPD. Thus, in the columns labeled "Investment Grade, Conditional" and "Non-Investment Grade, Conditional", we look back two years and condition the sample so that none of the firms experience any downgrades prior to the event. This conditioning reduces the monthly sample sizes of firms available during the 27 month period for investment grade to between 273 and 297 firms, and for non-investment grade to between 104 and 121 firms.

Table 4 indicates that with the $\mathrm{M}$ model, for investment grade firms, the differences in RNPD between the downgraded firms and the baseline firms are significant at the $99 \%, 95 \%$ and $90 \%$ levels 10, 11 and 12 months prior to the event, respectively. However, when the sample is conditioned for no previous downgrades, as in the "Investment Grade, Conditional" group, the significance at the $95 \%$ and $90 \%$ levels occurs 1 and 5 months prior to the event, respectively.

For the non-investment grade firms the RNPD are higher. At 2 years, or 24 months, prior to the event window, the Raw RNPD is $11.8 \%$, and the Med is $0.3 \%$, close to zero as expected. 
However, one month before the event, the Raw RNPD for the downgraded firms rises to $36.8 \%$, and the Med rises to $14.7 \%$. These differences are significant at the $99 \%, 95 \%$ and $90 \%$ levels 18, 19 and 22 months prior the downgrade event window, respectively. Once again, when the sample of non-investment grade firms is conditioned for no previous downgrades, as is the "NonInvestment Grade Conditional" group, the significance at the 95\% and 90\% levels occurs 9 and 13 months prior to the event, respectively. ${ }^{26}$

Instead of presenting 15 other tables for the $\mathrm{M}$ and $\mathrm{G}$ models, Table 5a summarizes Table 4 and all the other possible tables, using one summary row for each possible table. ${ }^{27}$ Thus, in Table 5a the columns present the following information: 1) the model (M or $\mathrm{G}), 2$ ) the rating category (IG or NIG), and 3) the magnitude of the rating migration (D-1, D-2, U-1, U-2). Then, for "All Events" and for the "Conditional" events, we present the number of months prior to the event that the Med is significantly different from zero at the 95\% and 90\% levels, and the number of observations. ${ }^{28}$

This summary table illustrates that one or both of these models is able to detect all unconditional rating migrations months before the event. The event with apparently the least detectable information is for the investment grade firms that exhibit upgrades of 2 or more rating categories. This may not be surprising because for investment grade firms there are very few firms that have rating upgrades of 2 or more rating categories. In fact, when comparing the number of firms exhibiting rating upgrades to the smaller number of firms exhibiting rating upgrades of 2 or more rating categories, we find the sample size is reduced from 351 firms to 62 firms, respectively. Thus, the smaller sample significantly reduces the power of the nonparametric test.

Table 5a also shows that when the sample of events is conditioned for no previous migrations during the prior 24 months, the sample size of available firms is significantly reduced. This reduced sample size reduces the power to statistically detect Med differences, and thus the number of months of early detection of the coming event is generally reduced. However, there are a few instances where this conditioning does not change the early detection, and in one case, for the non-investment grade firms experiencing rating changes of up 1 or more rating categories (NIG, U-1), conditioning on no previous rating changes actually improves the early detection for the M and G Short RNDP's.

Table 5a seems to indicate that with both models the larger risk neutral probabilities of default of the non-investment grade firms do not contain earlier information about rating migrations than those of the investment grade firms. Furthermore, all these risk neutral default probabilities do not seem to detect the rating downgrades any earlier than they detect the rating upgrades. These default probabilities, in general, seem to detect the impending larger rating migrations of down or up 2 or more rating categories later than they detect these same migrations with the down or up 1 or more rating category added to the sample. Perhaps this is because of the increased sample size and added power.

\footnotetext{
${ }^{26}$ In Table 4 and in the following tables, these test statistics assume independence in the time series of default probabilities. The events themselves are independent. However, there are more firms than events, and thus there may be some overlap in the stock prices of the event samples. Because of common market factors in the stock prices, these events may not be completely independent, and thus these test statistics may overstate significance.

${ }^{27}$ The more detailed tables are available.

${ }^{28}$ The number of observations reported is the maximum over the 24 months prior to the event.
} 
Table $5 \mathrm{~b}$ is a summary of Table $5 \mathrm{a}$ where the criteria is to indicate which risk neutral default probability detects the impending rating change the earliest. Both the $\mathrm{M}$ and $\mathrm{G}$ models are well represented, and the $\mathrm{M}$ model seems to do better for the investment grade firms, while the $\mathrm{G}$ model seems to do better for the non-investment grade firms. ${ }^{29}$ For the $\mathrm{G}$ model, the Short default probability appears to perform better for the non-investment grade firms, especially for the downgrades, while the Total and Forward default probabilities seem to perform better for the investment grade firms that upgrade. For the conditional sample, the $\mathrm{M}$ model seems to perform better for the upward rating migrations, while the $\mathrm{G}$ model seems to do better for the noninvestment grade downward rating migrations.

If the Med risk neutral default probabilities are actually increasing (decreasing) during the 24 months prior to the rating downgrade (upgrade) as Table 4 and the Figures $2 \mathrm{a}-2 \mathrm{~d}$ seem to reveal, then perhaps a Cox-Stuart paired sign test for trend in the data series could detect whether the trend is significant. Table 6 examines the trend in the $M$ and $G$ default probabilities for both the investment grade and non-investment grade firms and for each class of rating downgrade and upgrade.

A time series of observations is said to exhibit an upward (downward) trend if the magnitudes of the later observations tend to be greater (less) than the magnitudes of earlier observations. The downgraded firms should exhibit positive trend, and the upgraded firms should exhibit negative trend. Table 6 presents the number of positive pairs ( 24 months $=12$ pairs), and the associated p-value with the $5 \%$ cutoff set at .95 for positive trends and .05 for negative trends. In the analysis of the upward trend in the risk neutral default probabilities for those firms which will be downgraded, the M model shows significant positive trend in 7 of the 8 cases at the $95 \%$ level. Only for the investment grade down 2 or more rating categories is the $\mathrm{M}$ model not significant at the $95 \%$ level, but even this is significant at the $90 \%$ level. The G model also shows 7 of the 8 downgrade cases are significant at the 95\% level for the Total and Forward RNPD, and the only case which is not significant is the non-investment grade down 2 or more rating categories. The G Short RNPD shows significant trend at the 95\% level in 6 of the 8 cases, and only the two conditional investment grade downgrade cases are not significant.

The analysis of the downward trend in the risk neutral default probabilities for those firms that will be upgraded again shows that the $M$ model is significant in 7 of the 8 cases at the $95 \%$ level for 7 of the 8 rating upgrade cases. Only the unconditional investment grade firms upgraded by one or more rating categories is not significant at the $5 \%$ level, and even it is significant at the $10 \%$ level. For these firms experiencing rating upgrades, the G model's Short RNPD is significant at the $95 \%$ level in all 8 cases. However, the $\mathrm{G}$ model's Total and Forward RNPD show significant downward trend in 5 of the 8 cases. The G Short RNPD again appears to detect significant information, that is then removed from the Forward and diminished in the Total RNPD.

\footnotetext{
${ }^{29}$ However, these model differences in statistical significance of early detection of a rating change are slight, and do not imply that one model is better than the other for a particular class of firms.
} 


\subsubsection{Ex-Post versus Ex-Ante Information}

The above event study examines whether the available market information and a particular model can reveal information about the impending rating change prior to the event. Alternatively, without knowing ex-ante which firms are going to experience rating migrations, we could test whether each model calibrated with available market information is able to forecast which firms in any specific rating category are more likely ex-post to experience a rating migration. In this section, we examine 16 rating categories, ranging from AAA, down to B-.

Obviously, the probability of a particular firm in a specific rating category being upgraded or downgraded is not necessarily equally likely for any one rating category, nor would it be the same across all rating categories. For example, the probability of a AAA firm being upgraded is zero, and its probability of being downgraded is positive, while the probability of a BBB firm being upgraded or downgraded is positive, nor is it necessarily the case that the probability of a downgrade is equal for a AAA or BBB firm. However, if we randomly divide all firms in each rating category into three equal groups, then for large samples and without any additional information we would expect an equal number of firms from each of the three groups to be upgraded, downgraded, or stay the same. Alternatively, if we use the additional information of each model's risk neutral probability of default to divide the firms into three categories based on High, Medium, and Low default probabilities, then we might expect more firms in the High (Low) group to be downgraded (upgraded) than firms in the Low (High) group.

Tables $7 \mathrm{a}$ and $7 \mathrm{~b}$ illustrate precisely this idea for the $\mathrm{M}$ and $\mathrm{G}$ models, respectively, using the G model's Short risk neutral default probability. Table 7a, Panel A, examines the M model looking 2 quarters ahead to see which firms migrate either up, down, or stay in the same rating category, while Panel B answers the same question looking 4 quarters ahead. In Panel A, we compare the downward rating migrations of those firms that have High RNPD to those firms that have a Low RNPD, for each of the 16 rating categories. We find that firms with a High RNPD migrated down more than did firms with a Low RNPD. The Down p-value indicates that these differences are significant at the $95 \%$ (90\%) level in 15 (16) of the 16 possible rating categories. ${ }^{30}$

Similarly, when looking 2 quarters ahead at firms that migrated up, those firms in the group with Low RNPD had many more firms migrate up than those firms in the group with High RNPD in 13 of the 15 rating categories (the AAA cannot migrate up). The Up p-values indicate that these differences are significant at the $90 \%$ level for 12 of the 13 cases. The results for the $G$ Short model show a similar pattern. Looking two quarters ahead, the High group migrated down more than the Low group in all 16 cases with 15 of the 16 cases showing statistical significance at the $90 \%$ level. For upgrades, 14 of the 15 Low groups had more upgrades than the High group with 12 of the 14 being statistically significant at the $90 \%$ level.

\footnotetext{
${ }^{30}$ Since these p-values are based on differences and because most stocks are positively correlated, these p-values actually understate the significance.
} 
These results are very similar when looking 4 quarters ahead instead of 2 quarters ahead for both the $\mathrm{M}$ and the $\mathrm{G}$ models. Also, looking both 2 and 4 quarters ahead, firms in the high RNPD group experienced more downgrades (for all rating categories) than in the low RNPD group. Also, in 14 of the 15 rating categories where it is possible to experience an upgrade, more firms in the low RNPD group were upgraded than in the high RNPD group.

These tests indicate that risk neutral default probabilities from option models might be used in a fixed income investment strategy revealing which corporate bonds to buy or sell. Such a test would ideally require a more precise identification of the event date and actual daily prices of traded corporate bonds. However, most corporate bond data bases utilize matrix bond prices ${ }^{31}$ because these bonds are illiquid.

\subsection{Information in Risk Neutral Default Probabilities About Migrations to Default}

In this section we examine the behavior of the risk neutral default probabilities of the group of firms in our sample that actually migrated down to a default rating. In our data set of firms on Compustat with ratings by Standard and Poors this is a small sample of firms. Initially, we had 13 firms that defaulted during the 1987-1996 time period and had sufficient CRSP and Compustat data. However, when we eliminate those firms that do not have sufficient observations or for which the models do not converge, we are left with an even smaller sample of 8 firms at the event date.

In Table 8, which is similar to the previous Table 4, we report results for both the $\mathrm{M}$ and $\mathrm{G}$ models 24 months prior to the quarter of the default event and 3 months during the default event. For both the $\mathrm{M}$ and the $\mathrm{G}$ models, we report monthly numbers for the Raw risk neutral default probability, the median adjusted default probability ${ }^{32}$, the percent of these differences that are positive, the sign test p-value, the average rating of the defaulting firms, and the number of monthly observations.

For the M model, Table 8 shows that 24 months prior to default 4 of these firms have a median Raw RNPD of $32.8 \%$, which differs from the median of each cohort baseline by $0.42 \%$, and the average rating of these firms is 15.5 (which is between $\mathrm{B}+$ and $\mathrm{B}$ ). The raw RNPD rises from $32.8 \%$ to $83 \%$ in the last month before the event. Because this small sample is not conditioned on having no previous rating changes in the prior 24 months, the average firm rating has dropped to 20.3 (which is between CCC and CCC-). Also, just before the default event there are 7 and 8 firms in the $\mathrm{M}$ and $\mathrm{G}$ samples, respectively. The median adjusted default probability has increased to a maximum of $41.6 \% 3$ months prior to the event and is $17.6 \%$ one month prior to the event. The sign test on this difference for the M model is "significant" at the $95 \%$ level 8 months prior to the event, however caution should be taken in interpreting the significance due to the small sample size.

In Table 8 the $\mathrm{G}$ model's RNPD shows behavior similar to the M model. However, the $\mathrm{G}$ model's Short RNPD appears to be more consistent. This Short Raw RNPD is between 0\% and $2.3 \%$ during the period 24 months and 9 months prior to the default event. Then this Short RNPD

\footnotetext{
${ }^{31}$ Corporate bonds are not liquid and matrix bond prices are constructed. Matrix bond prices are prices that are adjusted and interpolated from other bond trades or quotes of bonds of similar rating, maturity, and coupon.

${ }^{32}$ Here the cohort is B- for all ratings below B- due to data limitations. Thus, the median adjusted probability will be overstated.
} 
increases monotonically up to 54.3\% one month prior to the event. The Short median adjusted default probability also increases from near zero up to $54.1 \%$ one month before the default event. The sign test for the G model's Short median adjusted RNPD is significant at the 99\% level 7 months prior to the event, however this significance should also be interpreted with caution due to the small sample size.

The G model's Short risk neutral default probability appears to indicate a significant probability of defaulting within 6-12 months of the event. This is consistent with the duration of the short term liabilities which was about 7 or 8 months. In fact, as the Short default probability rises, the term structure of default probabilities actually flattens 5 months before default, and then inverts 2 months before the default. Note that in the final month before the default event the Short probability (54.3\%) actually rises to be above the forward probability (32.9\%).

The G model's Short default probability seems to add additional information to the analysis of default risk, both about the timing of an impending default stemming from problems with current liabilities and about the shape of the term structure of default probabilities. 


\section{Conclusion}

This paper has used the option models of Merton and Geske and market data to estimate a ten year time series of risk neutral default probabilities for between 600 and 1000 firms during the period 1987-1996. Then the relation between these default probabilities and the events of rating migrations up, down, and to default are analyzed using the changes in Standard and Poors composite ratings reported quarterly by Compustat. It is found that both the Merton and Geske models produce default probabilities which indicate that the market anticipates these impending rating changes and defaults months prior to the actual event with considerable statistical significance. It is also found that both models do about equally well for investment grade firms which have lower default probabilities as for non-investment grade firms which have higher default probabilities. Both models also appear to as well with rating upgrades as with rating downgrades, and large rating changes do not necessarily have more or earlier significance than smaller rating changes. However, conditioning the sample on no rating changes 24 months prior to the event reduces the sample size, the statistical power, and the significance of early migration detection by the changes in these risk neutral default probabilities. This is the typical event study which examines whether a joint test using only the available market information and a particular model can reveal information about the impending rating change prior to the event. Alternatively, without knowing ex-ante which firms are going to experience rating migrations, we test whether each model calibrated with available market information is able to significantly forecast for any specific group of firms, which ones are more likely ex-post to experience a rating migration. We find that both the Merton and the Geske model produce default probabilities that are capable of forecasting which firms are more likely to experience a future rating migration. The Geske model, which incorporates multiple default opportunities, produces a term structure of default probabilities. The Geske Short probability, which reflects the tendency to default on current liabilities and short term debt appears to contain significant information about impending rating migrations and default. In fact for the default cases, which is a much smaller sample, the term structure of default probabilities inverts prior to the default event, and the Short default probability rises above the Forward default probability two months before the actual default. Finally, since both the rating migrations and defaults are detected months before the actual events and thus they do not appear to be surprises to the market, default may be as well or better modeled as a diffusion process than as a Poisson event. 
References

Altman, Edward I., R. Haldeman, and P. Narayanan, 1977, "Zeta Analysis, A New Model to Identify Bankruptcy Risk of Corporations," Journal of Banking and Finance, June.

Altman, Edward I., 1986, "Bankruptcy and Reorganization," In Handbook of Corporate Finance, New York: John Wiley \& Sons, pp. 9.1-9.63.

Altman, Edward I., and D.L. Kao, 1991, "Corporate Bond Rating Drift: An Examination of Credit Quality Rating Changes Over Time," The Research Foundation of the Institute of Chartered Financial Analysts.

Black, F., and J.C. Cox, 1976, "Valuing Corporate Securities: Some Effects of Bond Indenture Provisions," Journal of Finance, 31, pp. 351-368.

Black, F., and M. Scholes, 1973, “The Pricing of Options and Corporate Liabilities," Journal of Political Economy, 81, pp. 399-418.

Blume, M., F. Lim, and A. C. McKinley,1997, "The Declining Credit Quality of US Corporate Debt: Myth or Reality," University of Pennsylvania, Wharton Working Paper, September.

Cox, J., and S. Ross, 1976,

Delianedis, G., R. Geske, and T. Corzo, 1998, "Credit Risk Analysis With Option Models: Estimation and Comparison of Actual and Risk Neutral Default Probabilities", UCLA, Anderson School Working Paper, August.

Duffie, D., and K. Singleton, 1997, “An Econometric Model of the Term Structure of InterestRate Swap Yields”, September, vol. 52, no. 4, pp.1287-1321.

Geske, R., 1977, “The Valuation of Corporate Liabilities as Compound Options," Journal of Financial and Quantitative Analysis, pp. 541-552.

Geske, R., 1979, “The Valuation of Compound Options,” Journal of Financial Economics, 7, pp. 63-81.

Geske, R., (1978), “The Pricing of Options With Stochastic Dividend Yield,” Journal of Finance, 33,2, May, pp. 617-625.

Geske, R. and H. E. Johnson, (1984), "The American Put Valued Analytically," The Journal of Finance, 39, 5, pp. 1511-1524.

Hite, G., and A. Warga, 1997, "The Effect of Bond-Rating Changes on Bond Price Performance", Financial Analysts Journal, May/June, pp. 35-51.

Jarrow, R., and S. Turnbull, 1995, "Pricing Derivatives on Financial Securities Subject to Credit Risk," Journal of Finance, 50,1, pp. 53-85. 
Kim, H., K. Ramaswamy, and S. Sunderesan, 1993, "Valuation of Corporate Fixed-Income Securities", Financial Management (Special issue on financial distress), 22,3, pp.60-78.

KMV Corporation, 1993, Credit Monitor Overview, San Francisco, California.

Leland, H., 1994, "Corporate Debt Value, Bond Covenants, and Optimal Capital Structure," Journal of Finance, 49,1, pp. 1213-1252.

Longstaff, F. A., and E.S. Schwartz, 1995, "A Simple Approach to Valuing Risky Fixed and Floating Rate Debt," Journal of Finance, 50, Journal of Finance, 50, pp. 789-819.

Lucas, D. J., 1995, "Measuring Credit Risk and Required Capital," Derivative Credit Risk: Mason, S. P. and S. Bhattacharya, 1981, "Risky Debt, Jump Process, and Safety Covenants," Journal of Financial Economics, 9, pp. 281-307.

Masters, B., 1997, "Credit Metrics, Credit Risk, and Credit Derivatives”, Berkeley Program in Finance, San Diego, September.

Merton, R. C., 1973, “Theory of Rational Option Pricing”, Bell Journal of Economics and Management Science, 4, Spring, pp. 141-183

Merton, R. C., 1974, "On the Pricing of Corporate Debt: The Risk Structure of Interest Rates," Journal of Finance, 29, pp. 449-470.

Turnbull, S., 1979, “Debt Capacity,” Journal of Finance, 34, pp. 931-940. 
Figure 1

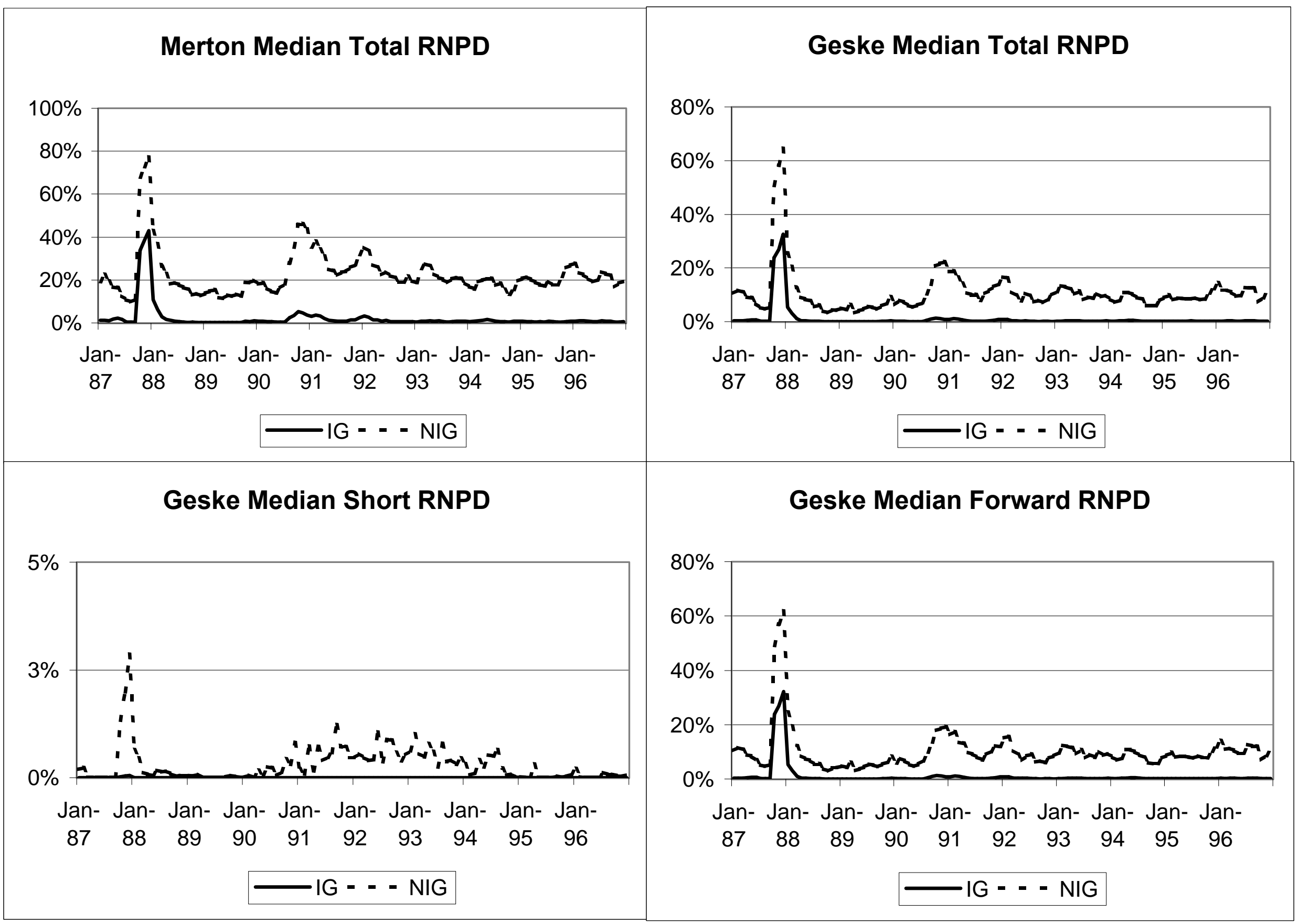


Figure 2a

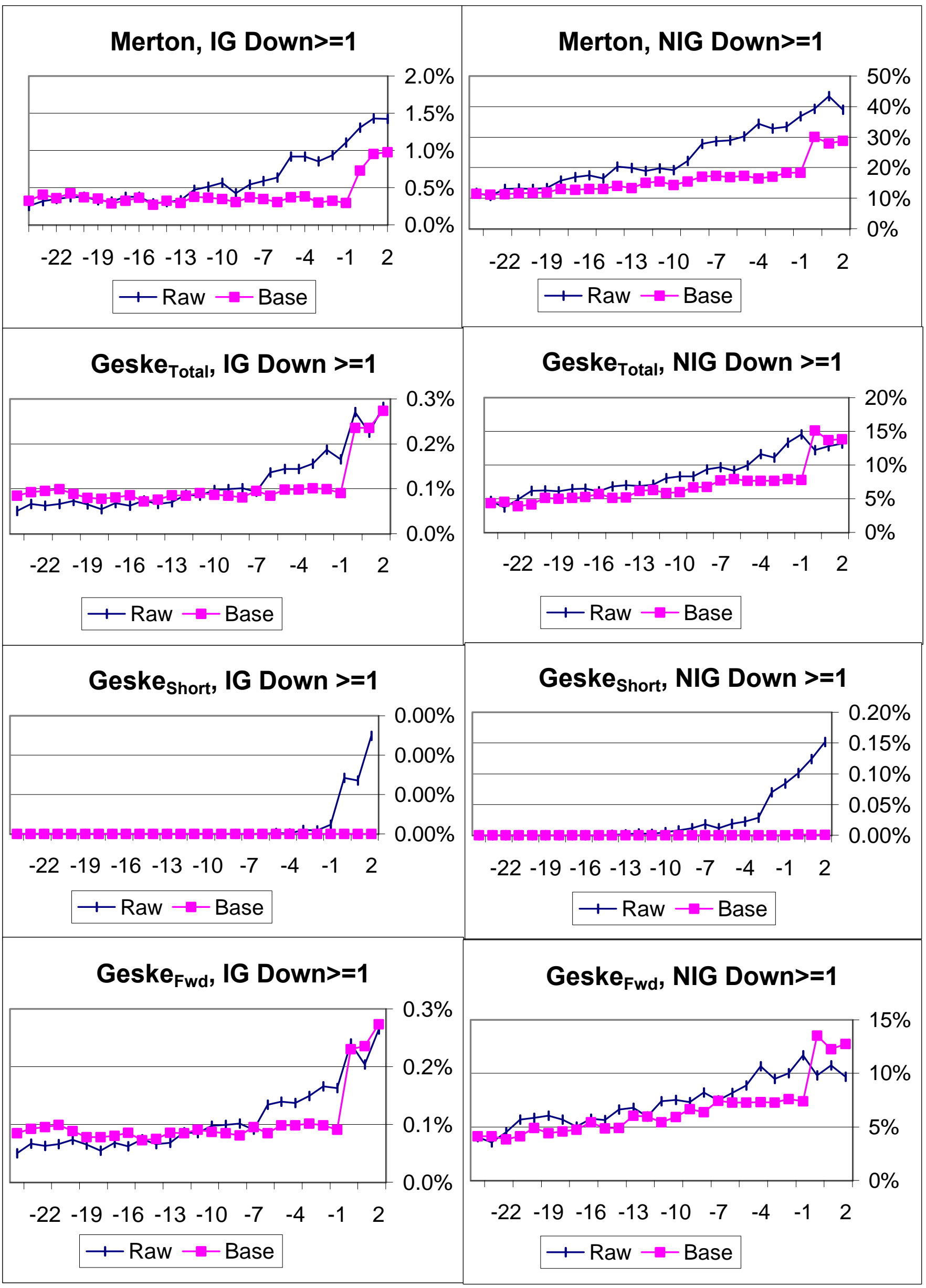


Figure 2b

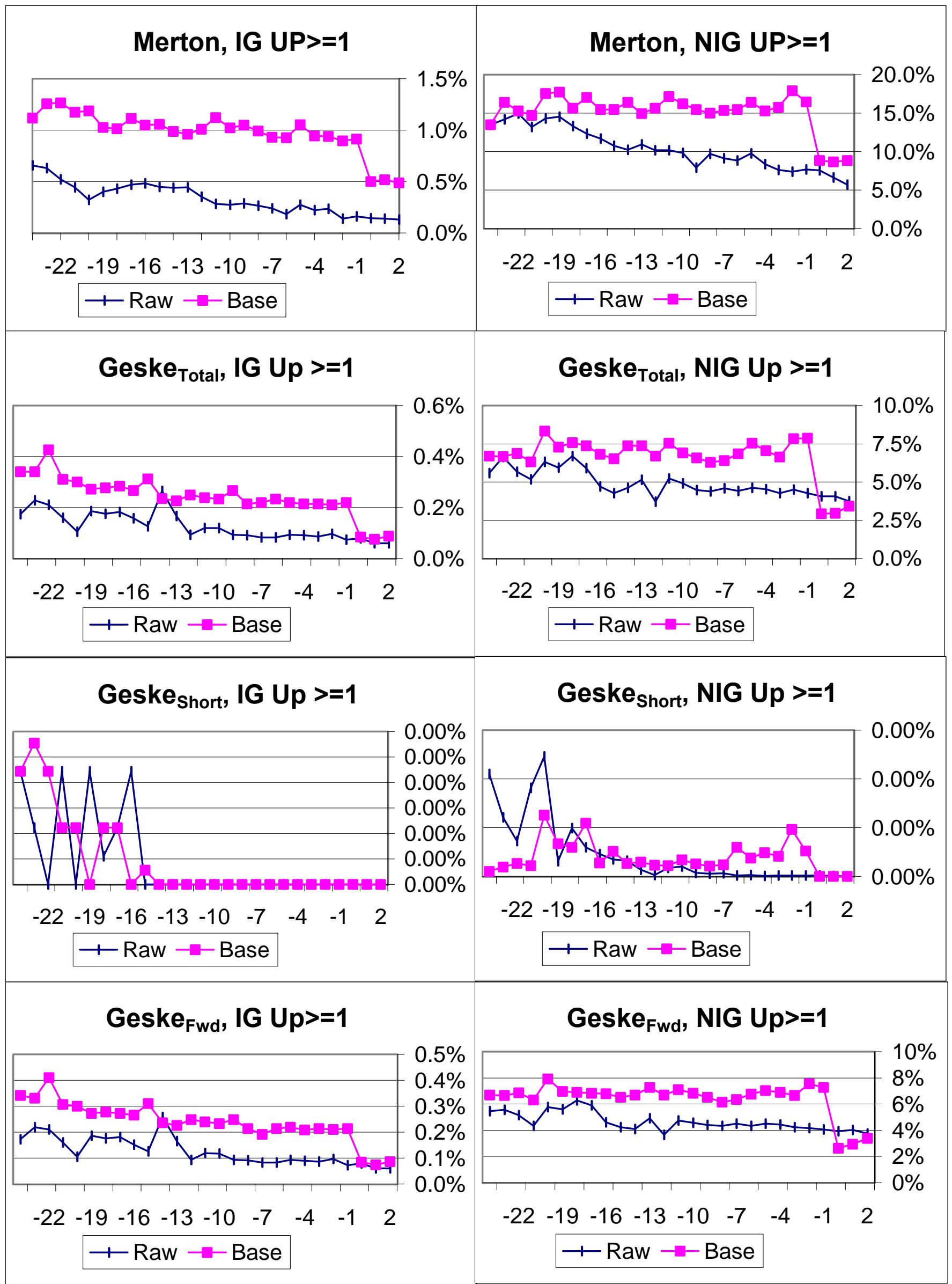


Figure 2c

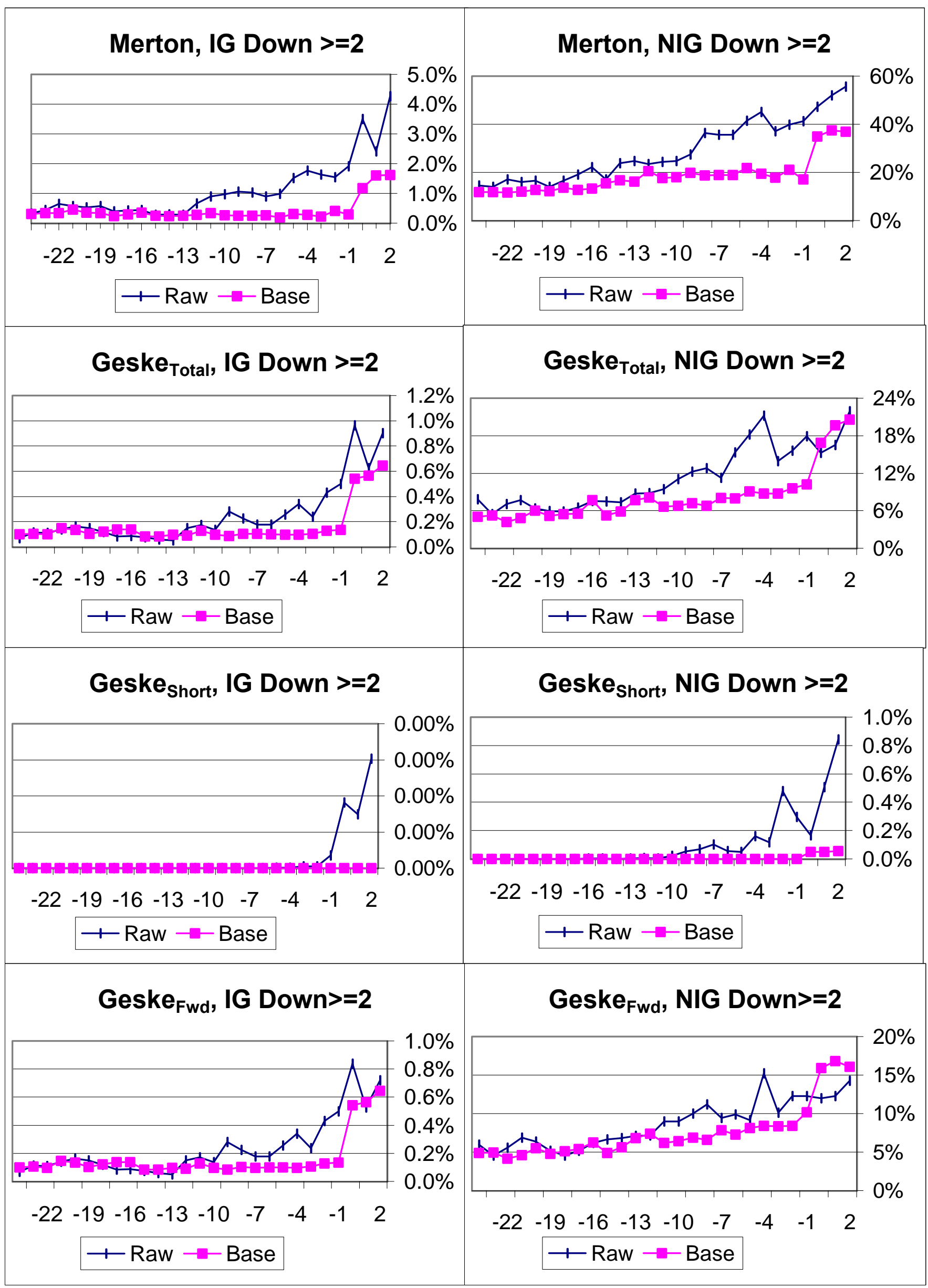


Figure 2d

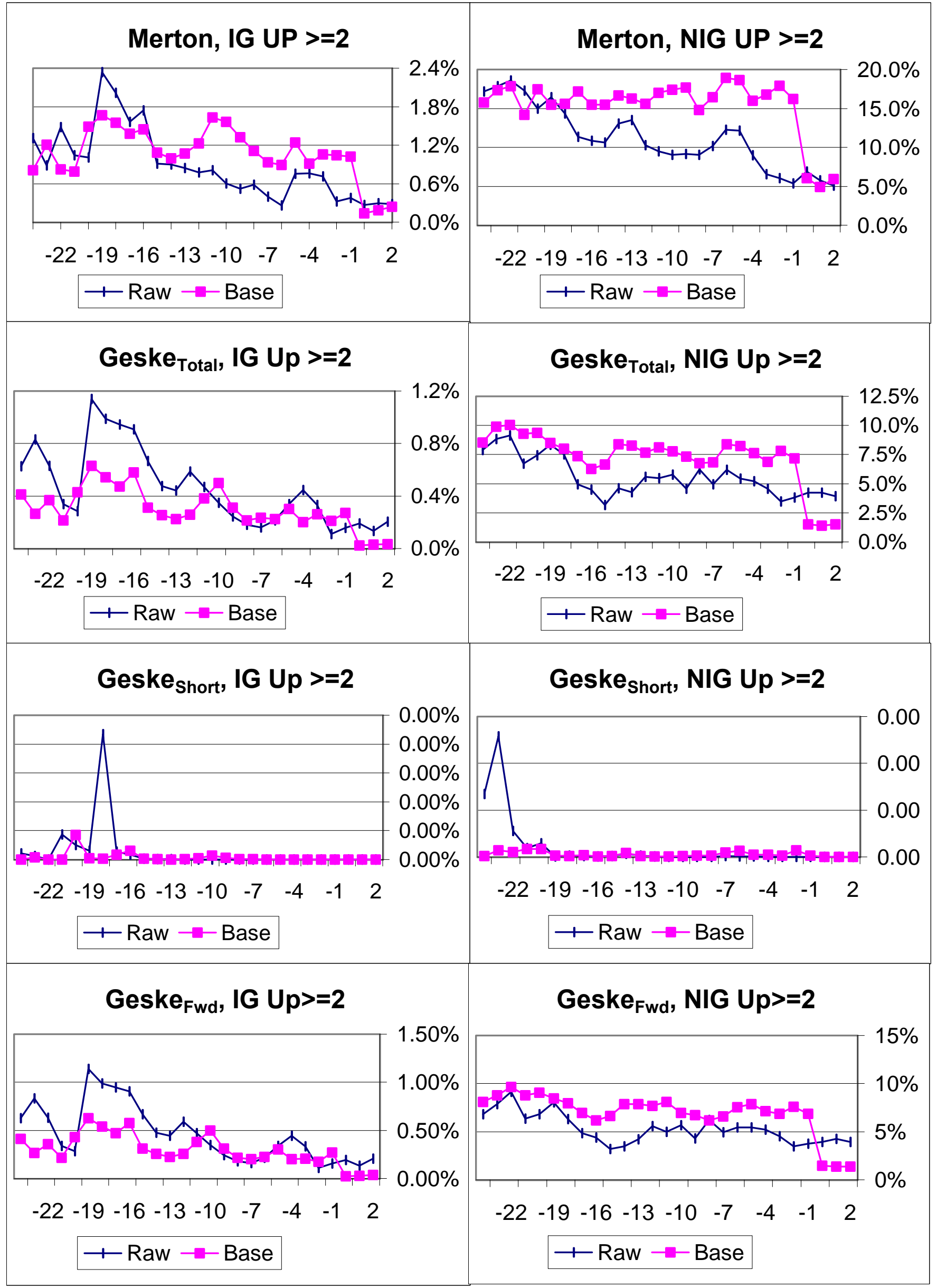




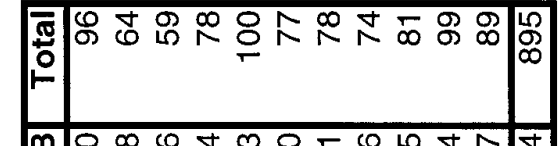

m

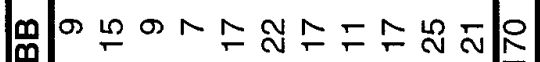

m

盈

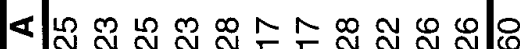

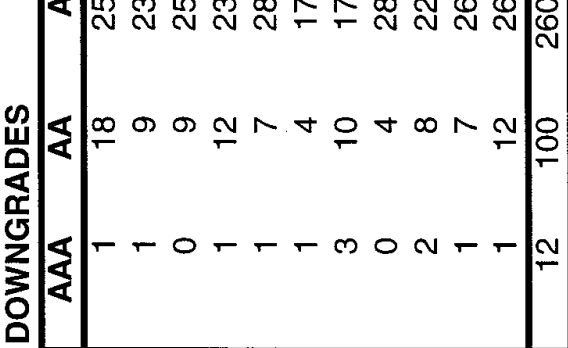

बृँ

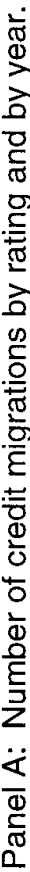

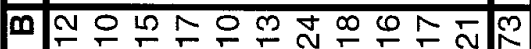

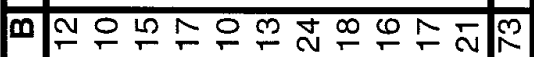

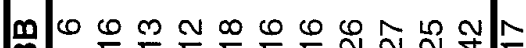

苗

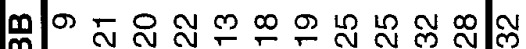

m

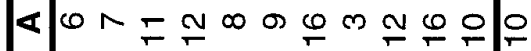

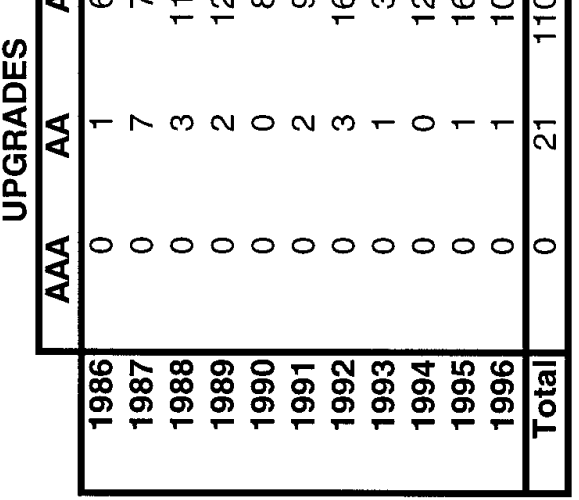

递

คे

ส)

들

弯

윽 웅

त् के

吠 艺

응

$\pm$

$\varangle \mathrm{o}$

㐫 흐

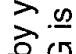

을

음 $\frac{0}{\frac{0}{\sigma}}$

旁离

E

존

응 웅

뜐

흘

흥

ปั

tั․ㅡㅁ

产 호

들 음

$\frac{\dot{\omega}}{\stackrel{0}{c}}$

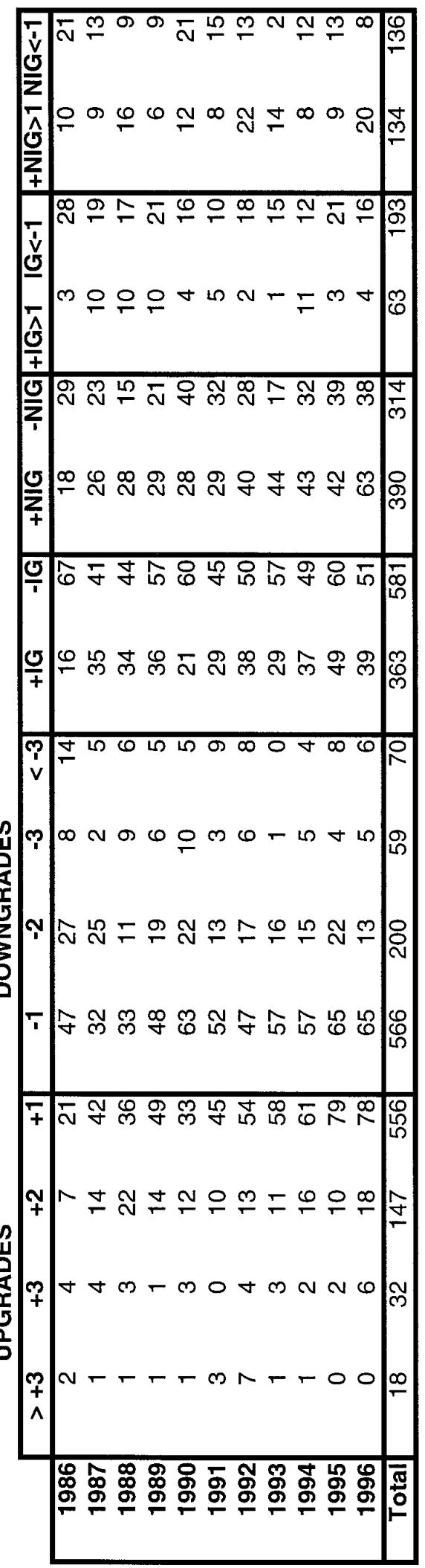




\section{Table 3}

Panel A: $\quad$ Credit rating transition rates. Event transition rate measures the frequency of upgrades and downgrades. The event transition magnitude rate is the transition frequency weighted

by the severity of the event.

\begin{tabular}{|c|c|c|c|c|c|c|c|c|}
\hline & \multicolumn{4}{|c|}{ Event Transition Rate } & \multicolumn{4}{|c|}{ Event Transition Magnitude Rate } \\
\hline & IG-UP & IG-DN & NIG-UP & NIG-DN & IG-UP & IG-DN & NIG-UP & NIG-DN \\
\hline 1987 & 0.094 & 0.110 & 0.126 & 0.111 & 0.134 & 0.195 & 0.174 & 0.203 \\
\hline 1988 & 0.089 & 0.115 & 0.139 & 0.075 & 0.120 & 0.206 & 0.244 & 0.189 \\
\hline 1989 & 0.096 & 0.152 & 0.148 & 0.108 & 0.126 & 0.262 & 0.189 & 0.169 \\
\hline 1990 & 0.056 & 0.159 & 0.156 & 0.223 & 0.066 & 0.218 & 0.251 & 0.423 \\
\hline 1991 & 0.074 & 0.114 & 0.174 & 0.192 & 0.086 & 0.145 & 0.258 & 0.491 \\
\hline 1992 & 0.090 & 0.119 & 0.207 & 0.145 & 0.095 & 0.183 & 0.465 & 0.336 \\
\hline 1993 & 0.066 & 0.130 & 0.190 & 0.073 & 0.069 & 0.164 & 0.271 & 0.086 \\
\hline 199 & 0.082 & 0.108 & 0.156 & 0.116 & 0.108 & 0.153 & 0.196 & 0.203 \\
\hline & 0.100 & 0.123 & 0.138 & 0.129 & 0.107 & 0.195 & 0.175 & 0.211 \\
\hline & 0.071 & 0.093 & 0.165 & 0.099 & 0.080 & 0.140 & 0.230 & 0.146 \\
\hline Mean & 0.082 & 0.122 & 0.160 & 0.127 & 0.099 & 0.186 & 0.245 & 0.246 \\
\hline
\end{tabular}

Panel B: $\quad$ Average median debt to value and firm volatility for the baseline Merton and Geske models.

Debt to Value

Firm Volatility

\begin{tabular}{r|cccc|cccc|}
\cline { 2 - 9 } & $\mathbf{I G}_{\mathbf{M}}$ & $\mathbf{N I G}_{\mathbf{M}}$ & $\mathbf{I G}_{\mathbf{G}}$ & $\mathbf{N I G}_{\mathbf{G}}$ & $\mathbf{I G} \mathbf{G}_{\mathbf{M}}$ & $\mathbf{N I G}_{\mathbf{M}}$ & $\mathbf{I G}_{\mathbf{G}}$ & $\mathbf{N I G}_{\mathbf{G}}$ \\
$\mathbf{1 9 8 8}$ & 0.280 & 0.366 & 0.293 & 0.403 & 0.274 & 0.365 & 0.261 & 0.317 \\
$\mathbf{1 9 8 9}$ & 0.314 & 0.453 & 0.318 & 0.480 & 0.185 & 0.263 & 0.182 & 0.232 \\
$\mathbf{1 9 9 0}$ & 0.324 & 0.474 & 0.322 & 0.486 & 0.148 & 0.223 & 0.148 & 0.204 \\
$\mathbf{1 9 9 1}$ & 0.355 & 0.472 & 0.358 & 0.518 & 0.168 & 0.290 & 0.165 & 0.236 \\
$\mathbf{1 9 9 2}$ & 0.347 & 0.465 & 0.351 & 0.518 & 0.176 & 0.294 & 0.172 & 0.238 \\
$\mathbf{1 9 9 3}$ & 0.332 & 0.478 & 0.343 & 0.517 & 0.167 & 0.269 & 0.164 & 0.221 \\
$\mathbf{1 9 9 4}$ & 0.339 & 0.465 & 0.350 & 0.504 & 0.159 & 0.268 & 0.155 & 0.224 \\
$\mathbf{1 9 9 5}$ & 0.332 & 0.450 & 0.338 & 0.472 & 0.158 & 0.244 & 0.156 & 0.214 \\
$\mathbf{1 9 9 6}$ & 0.330 & 0.466 & 0.334 & 0.492 & 0.148 & 0.246 & 0.146 & 0.215 \\
Mean & 0.306 & 0.433 & 0.313 & 0.471 & 0.165 & 0.274 & 0.163 & 0.236 \\
\hline & 0.326 & 0.452 & 0.332 & 0.486 & 0.175 & 0.274 & 0.171 & 0.234 \\
\hline
\end{tabular}

Panel C: $\quad$ Average median baseline RNPD for the Merton and Geske models.

\begin{tabular}{|c|c|c|c|c|c|c|c|c|}
\hline & Merton & & $\mathrm{KE}_{\text {Total }}$ & & $\mathrm{KK}_{\text {Short }}$ & & $S K E_{F W d}$ & \\
\hline & IG & NIG & IG & NIG & IG & NIG & IG & NIG \\
\hline 1987 & 0.105 & 0.296 & 0.072 & 0.205 & 0.000 & 0.006 & 0.071 & 0.200 \\
\hline 1988 & 0.022 & 0.212 & 0.009 & 0.093 & 0.000 & 0.002 & 0.009 & 0.087 \\
\hline 1989 & 0.004 & 0.147 & 0.001 & 0.054 & 0.000 & 0.000 & 0.001 & 0.051 \\
\hline 1990 & 0.020 & 0.262 & 0.005 & 0.113 & 0.000 & 0.002 & 0.004 & 0.101 \\
\hline 1991 & 0.018 & 0.286 & 0.005 & 0.130 & 0.000 & 0.005 & 0.005 & 0.115 \\
\hline 1992 & 0.012 & 0.242 & 0.003 & 0.102 & 0.000 & 0.006 & 0.003 & 0.092 \\
\hline 1993 & 0.008 & 0.218 & 0.002 & 0.106 & 0.000 & 0.006 & 0.002 & 0.099 \\
\hline 1994 & 0.009 & 0.177 & 0.002 & 0.082 & 0.000 & 0.003 & 0.002 & 0.080 \\
\hline 1995 & 0.006 & 0.204 & 0.002 & 0.092 & 0.000 & 0.000 & 0.002 & 0.088 \\
\hline 1996 & 0.008 & 0.214 & 0.002 & 0.111 & 0.000 & 0.001 & 0.002 & 0.107 \\
\hline Mean & 0.021 & 0.226 & 0.010 & 0.109 & 0.000 & 0.003 & 0.010 & 0.102 \\
\hline
\end{tabular}




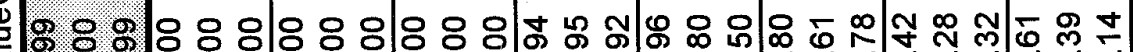

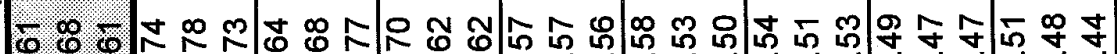
+ - $\begin{gathered}0 \\ \text { o }\end{gathered}$

N.

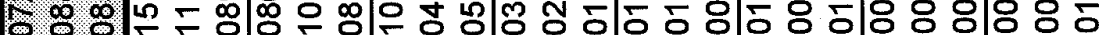
إس

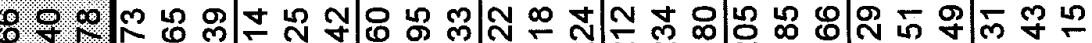

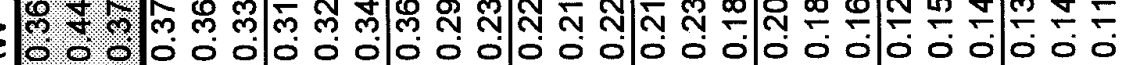

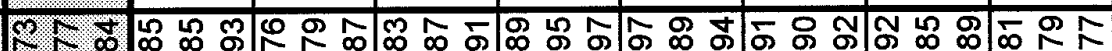

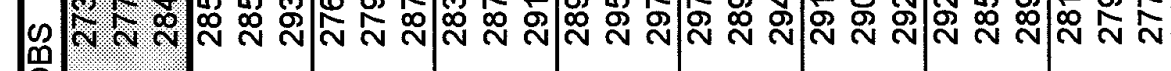

ד ถ

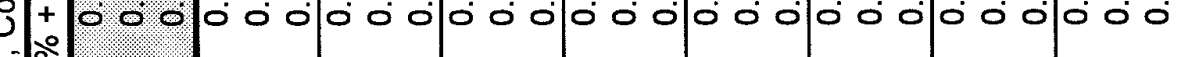

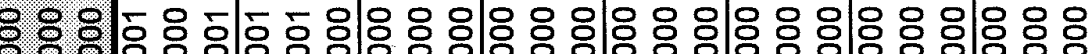
V 范

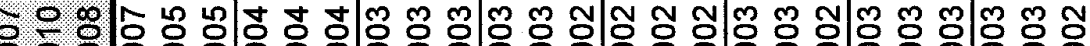

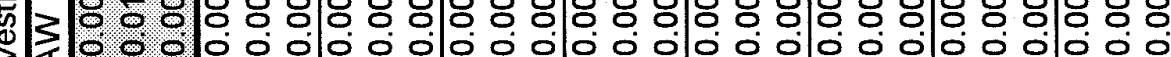
도

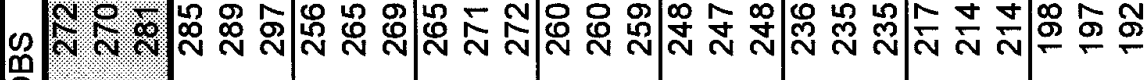
$\gtrsim \bar{c}$ 管

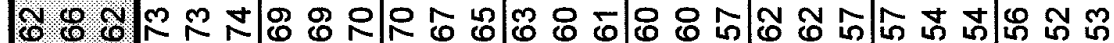

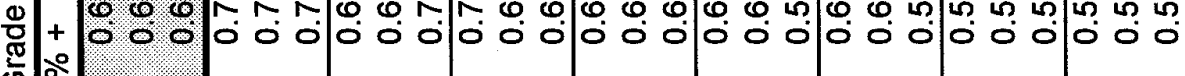

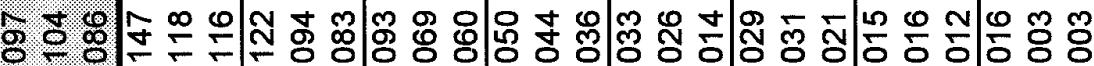

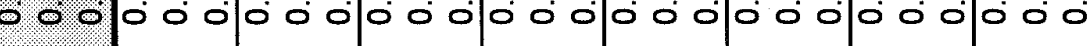

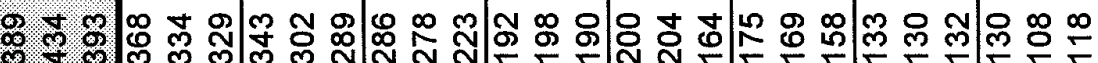
雨 区

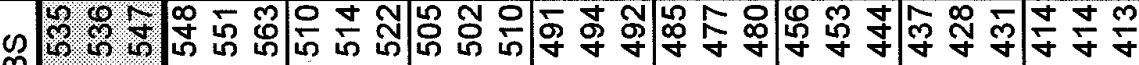

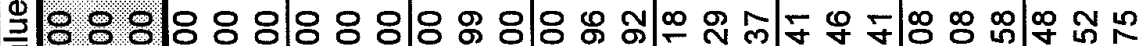

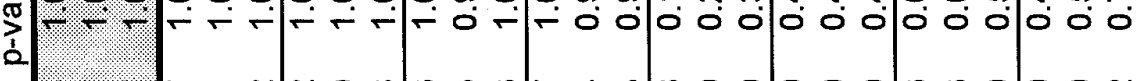

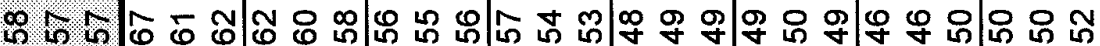

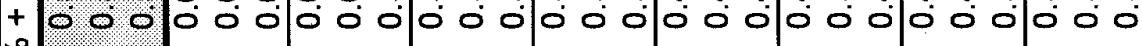
$\frac{9}{\pi}$

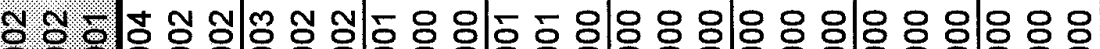

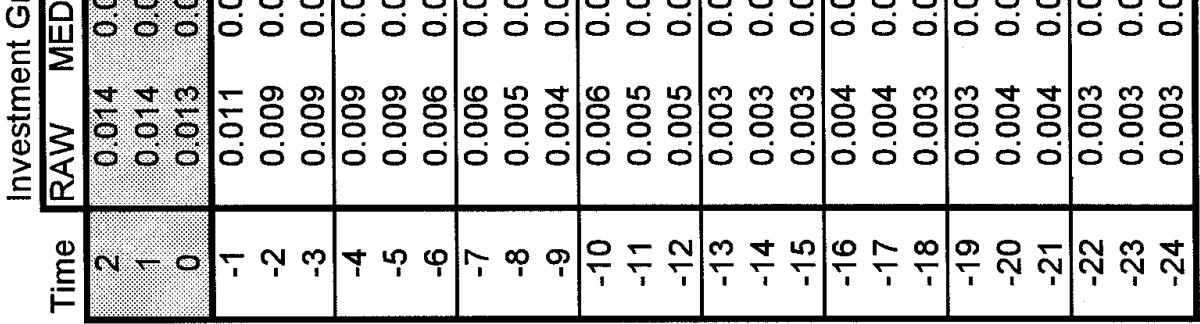




\section{Table 5A}

Number of months prior to the event date that the median adjusted RNPD (MED) is significant. Significance levels for $95 \%$ and $90 \%$ are noted. The two samples are all events and the events conditional on no rating change within the previous 8 quarters. The two models are Merton- $M$ and Geske-G. The Geske model has 3 RNPD to report: T-Total, S-Short, and F-Forward. Magnitudes are denoted as down (D) and up (U) with rating changes of magnitude one or more (1) or two or more (2).

All Events Conditional Events

Model Class Mag $95 \% \quad 90 \%$ Obs $\quad 95 \% \quad 90 \%$ Obs

\begin{tabular}{|ccc|rrr|rrr|}
\hline M & IG & D-1 & 11 & 12 & 563 & 1 & 5 & 293 \\
M & IG & D-2 & 12 & 17 & 188 & 5 & 7 & 82 \\
M & IG & U-1 & 24 & 24 & 359 & 24 & 24 & 200 \\
\hline M & NIG & D-1 & 19 & 5 & 62 & 1 & 6 & 31 \\
M & NIG & D-2 & 13 & 20 & 122 & 8 & 8 & 44 \\
M & NIG & U-1 & 18 & 20 & 373 & 24 & 24 & 167 \\
M & NIG & U-2 & 16 & 16 & 126 & 17 & 18 & 51 \\
\hline G-T & IG & D-1 & 2 & 5 & 535 & 1 & 6 & 295 \\
G-T & IG & D-2 & 5 & 15 & 172 & 5 & 5 & 83 \\
G-T & IG & U-1 & 24 & 24 & 351 & 16 & 17 & 201 \\
G-T & IG & U-2 & 0 & 0 & 62 & 0 & 0 & 31 \\
\hline G-T & NIG & D-1 & 6 & 11 & 273 & 3 & 5 & 117 \\
G-T & NIG & D-2 & 6 & 11 & 111 & 0 & 4 & 40 \\
G-T & NIG & U-1 & 18 & 24 & 373 & 10 & 18 & 166 \\
G-T & NIG & U-2 & 17 & 18 & 125 & 11 & 17 & 51 \\
\hline G-S & IG & D-1 & 5 & 6 & 535 & 0 & 0 & 295 \\
G-S & IG & D-2 & 12 & 12 & 172 & 3 & 4 & 83 \\
G-S & IG & U-1 & 0 & 0 & 351 & 0 & 0 & 201 \\
G-S & IG & U-2 & 0 & 0 & 62 & 0 & 0 & 31 \\
\hline G-S & NIG & D-1 & 24 & 24 & 273 & 15 & 15 & 117 \\
G-S & NIG & D-2 & 24 & 24 & 111 & 15 & 15 & 40 \\
G-S & NIG & U-1 & 6 & 11 & 373 & 7 & 12 & 166 \\
G-S & NIG & U-2 & 4 & 11 & 125 & 12 & 15 & 51 \\
\hline G-F & IG & D-1 & 2 & 5 & 535 & 1 & 5 & 295 \\
G-F & IG & D-2 & 5 & 15 & 172 & 5 & 5 & 83 \\
G-F & IG & U-1 & 24 & 24 & 351 & 12 & 17 & 201 \\
G-F & IG & U-2 & 0 & 0 & 62 & 0 & 0 & 31 \\
\hline G-F & NIG & D-1 & 4 & 4 & 273 & 3 & 3 & 117 \\
G-F & NIG & D-2 & 0 & 5 & 111 & 0 & 0 & 40 \\
G-F & NIG & U-1 & 17 & 24 & 373 & 10 & 18 & 166 \\
G-F & NIG & U-2 & 17 & 17 & 125 & 12 & 17 & 51 \\
\hline & & & & & & & &
\end{tabular}




\section{Table 5B}

Model which detects rating migrations the earliest and the number of months ahead of the event. Results are given for the $95 \%$ and $90 \%$ confidence level and for the samples of all events and the conditional events.

The two models are Merton- $M$ and Geske-G. The Geske model has

3 RNPD: T-Total, S-Short, and F-Forward. Rating migrations are denoted as either down (D) or up (U) and with magnitudes one or more (1) or two or more (2).

COND denotes the conditional sample and ALL is all events.

\begin{tabular}{|c|c|c|c|c|c|c|c|c|c|}
\hline & \multicolumn{2}{|c|}{ All $95 \%$} & \multicolumn{2}{|c|}{ All $90 \%$} & \multicolumn{2}{|c|}{ Cond $95 \%$} & \multicolumn{2}{|c|}{ Cond $90 \%$} \\
\hline & & Mon & Model & Mon & Model & Mon & Model & Mon & Model \\
\hline IG & $D-1$ & 11 & $M$ & 12 & $M$ & & $1 \mathrm{G}_{\mathrm{T}}$ & & $\begin{array}{ll}6 & \mathrm{G}_{\mathrm{T}}\end{array}$ \\
\hline$I G$ & D-2 & 12 & $\mathrm{G}_{\mathrm{S}}, \mathrm{M}$ & 17 & $M$ & & $5 \mathrm{G}_{\mathrm{T}}, \mathrm{M}$ & & $M$ \\
\hline IG & $U-1$ & 24 & $\mathrm{G}_{T}, \mathrm{M}$ & 24 & $\mathrm{G}_{\mathrm{T}}, \mathrm{M}$ & 24 & $M$ & 24 & $M$ \\
\hline IG & U-2 & 5 & $M$ & 5 & $M$ & & $M$ & & $M$ \\
\hline NIG & $D-1$ & 2 & $\mathrm{G}_{\mathrm{S}}$ & 24 & $\mathrm{G}_{\mathrm{S}}$ & & $\mathrm{G}_{\mathrm{S}}$ & 15 & $\mathrm{G}_{\mathrm{S}}$ \\
\hline NIG & D-2 & 24 & $\mathrm{G}_{\mathrm{S}}$ & 24 & $\mathrm{G}_{\mathrm{S}}$ & 15 & $\mathrm{G}_{\mathrm{S}}$ & 15 & $\mathrm{G}_{\mathrm{S}}$ \\
\hline NIG & U-1 & 24 & $\mathrm{G}_{F}$ & 24 & $\mathrm{G}_{\mathrm{F}}, \mathrm{G}_{\mathrm{T}}$ & 24 & $M$ & 24 & $M$ \\
\hline NIG & U-2 & 17 & $\mathrm{G}_{\mathrm{F}}, \mathrm{G}_{\mathrm{T}}$ & 18 & $\mathrm{G}_{\mathrm{T}}$ & 17 & $M$ & 18 & $M$ \\
\hline
\end{tabular}




\section{Table 6}

Cox-Stuart test for trend in median adjusted RNPD (MED). Sample has 12 paired observations of the MED for the Merton and Geske models. Test is conducted on investment grade (IG) and non-investment grade (NIG) classes of rating migrations, up or down, of magnitude 1 or 2.

The * denotes the sample which is conditioned on having trhe same rating in the previous 8 quarters. $\mathrm{NUM}+$ is the number of positive observations. ' $p$-value' is the test statistic.

\begin{tabular}{|c|c|c|c|c|c|c|c|c|c|}
\hline & & Merton & & Geske Short & & Geske Total & & Geske Forw & \\
\hline & & NUM + & $p$-value & NUM + & $p$-value & NUM + & p-value I & NUM + & $p$-value \\
\hline Down 1 & IG & 12 & 1.000 & 10 & 0.997 & 12 & 1.000 & 11 & 1.000 \\
\hline & NIG & 12 & 1.000 & 12 & 1.000 & 12 & 1.000 & 9 & 0.981 \\
\hline & $I G^{*}$ & 11 & 1.000 & 3 & 0.073 & 11 & 1.000 & 11 & 1.000 \\
\hline & $\mathrm{NIG}^{*}$ & 12 & 1.000 & 12 & 1.000 & 11 & 1.000 & 10 & 0.997 \\
\hline Down 2 & IG & 12 & 1.000 & 12 & 1.000 & 12 & 1.000 & 12 & 1.000 \\
\hline & NIG & 12 & 1.000 & 12 & 1.000 & 12 & 1.000 & 10 & 0.997 \\
\hline & $I G^{*}$ & 8 & 0.927 & 5 & 0.387 & 9 & 0.981 & 9 & 0.981 \\
\hline & $\mathrm{NIG}^{*}$ & 12 & 1.000 & 12 & 1.000 & 6 & 0.613 & 5 & 0.387 \\
\hline Up 1 & IG & 3 & 0.073 & 0 & 0.000 & 8 & 0.927 & 8 & 0.927 \\
\hline & NIG & 0 & 0.000 & 0 & 0.000 & 2 & 0.019 & 2 & 0.019 \\
\hline & $I^{*}$ & 0 & 0.000 & 0 & 0.000 & 5 & 0.387 & 6 & 0.613 \\
\hline & $\mathrm{NIG}^{*}$ & 0 & 0.000 & 0 & 0.000 & 1 & 0.003 & 1 & 0.003 \\
\hline Up 2 & IG & 2 & 0.019 & 0 & 0.000 & 4 & 0.194 & 4 & 0.194 \\
\hline & NIG & 0 & 0.000 & 0 & 0.000 & 1 & 0.003 & 3 & 0.073 \\
\hline & $1 G^{*}$ & 2 & 0.019 & 0 & 0.000 & 2 & 0.019 & 2 & 0.019 \\
\hline & $N I G^{*}$ & 0 & 0.000 & 0 & 0.000 & 0 & 0.000 & 0 & 0.000 \\
\hline
\end{tabular}




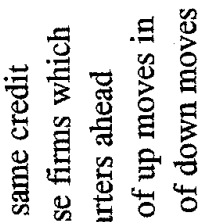

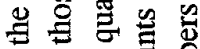
넝 승 है

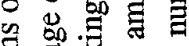

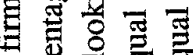
글

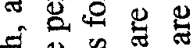

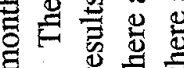

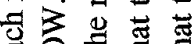
ज्ञ 里

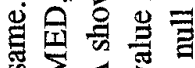

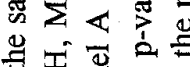
焉志宫

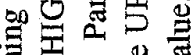

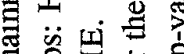

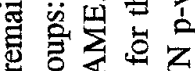
巳 究 ○范

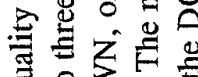
豆边。

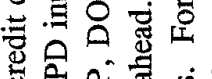

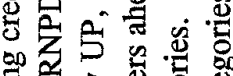

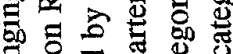

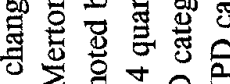
¿

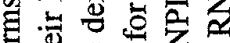

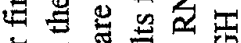

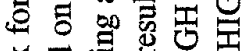

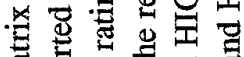

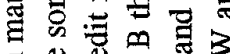

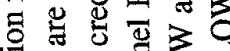

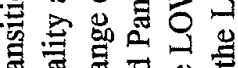
焉焉焉恶

\begin{tabular}{|c|c|c|c|c|}
\hline$\theta$ & $\begin{array}{lll}50 & 5 e & 5 e \\
0 & 5 & y \\
6 & \bar{a} & -i\end{array} \mid$ & $\mid \begin{array}{lll}20 & 20 & 80 \\
\infty & \infty & \square \\
0 & \infty & - \\
0 & \infty & -\end{array}$ & $\left|\begin{array}{ccc}0 & 0 & 50 \\
0 & b & \infty \\
m & 1 & 0 \\
m & \infty & 0\end{array}\right|$ & 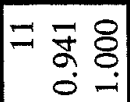 \\
\hline$\infty$ & 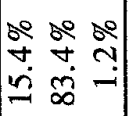 & $\left|\begin{array}{ccc}\infty & \infty & \Delta \\
n & \sigma & b \\
\infty & \dot{0} & 0 \\
& \infty & 0\end{array}\right|$ & 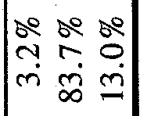 & $\stackrel{8}{8} 8$ \\
\hline \pm & $\left|\begin{array}{ccc}0 & 20 & 0 \\
0 & 0 & r \\
0 & \infty & 0 \\
\hdashline & \infty & 0\end{array}\right|$ & $\left|\begin{array}{ccc}0 & s & s \\
m & 0 & \infty \\
0 & \delta & m\end{array}\right|$ & $\left|\begin{array}{lll}50 & 50 & 50 \\
m & 0 & - \\
ن & 5 & 0\end{array}\right|$ & in 8 \\
\hline$\frac{\dot{\rho}}{m}$ & 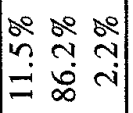 & 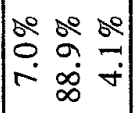 & 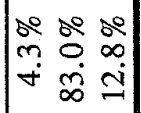 & n 8 \\
\hline$\stackrel{n}{\oplus}$ & $\begin{array}{ccc}\text { se } & \text { se } & \text { se } \\
0 & - & m \\
& \dot{n} & -1\end{array}$ & 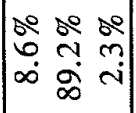 & 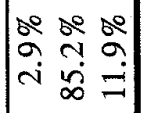 & m 8 \\
\hline+ & 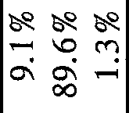 & $\left|\begin{array}{ccc}20 & 30 & 8 \\
0 & 0 & y \\
0 & 2 & \dot{y} \\
- & \infty & \end{array}\right|$ & 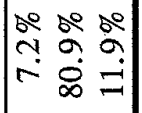 & 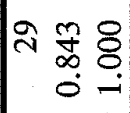 \\
\hline 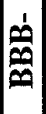 & $\begin{array}{ccc}0 & 0 & 0 \\
0 & r & m \\
0 & \infty & i\end{array}$ & 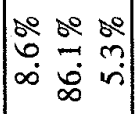 & 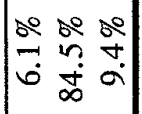 & $\mid \begin{array}{cc}9 & 0 \\
m & \infty \\
0 & 8 \\
0 & \end{array}$ \\
\hline$\frac{\infty}{\infty}$ & $\begin{array}{ccc}2 & 5 & 5 \\
m & 5 & 0 \\
0 & \infty & 0\end{array}$ & 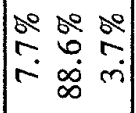 & $\mid \begin{array}{lll}\text { se } & \text { be } & \text { se } \\
n & -1 & 4 \\
\text { i } & 5 & 0\end{array}$ & 688 \\
\hline+ & $\begin{array}{ccc}\text { se } & \text { se } & \text { se } \\
- & \infty & = \\
\infty & \infty & \dot{\infty}\end{array}$ & $\left|\begin{array}{ccc}\Delta 0 & \text { se } & \text { se } \\
0 & -1 & 9 \\
r & \infty & 0\end{array}\right|$ & $\mid$\begin{tabular}{ccc}
0 & 0 & 0 \\
\hdashline & $a$ & \pm \\
$\dot{m}$ & 10 & 0
\end{tabular} & ผ \\
\hline$\dot{4}$ & $\begin{array}{lll}\text { se } & \text { se } & \text { se } \\
1 & 9 & + \\
\text { ni } & \text { a } & \text { i }\end{array}$ & 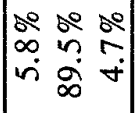 & 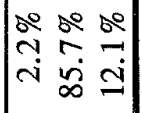 & 효 \\
\hline 4 & $\begin{array}{lll}2 & 2 & 2 \\
\infty & 0 & y \\
ن & n & 1\end{array}$ & 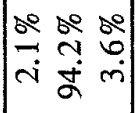 & $\mid \begin{array}{lll}\text { se } & \text { de } & \text { se } \\
0 & 7 & 0 \\
-1 & 0 & 0\end{array}$ & 용 \\
\hline \pm & 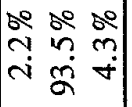 & 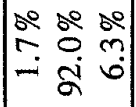 & $\mid \begin{array}{lll}0 & 5 & \text { se } \\
n & m & m \\
0 & 8 & 0\end{array}$ & 움 용용 \\
\hline$\sum$ & 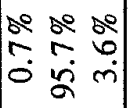 & 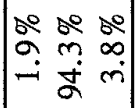 & $\mid \begin{array}{lll}00 & 0 & \text { se } \\
0 & 0 & \infty \\
ن & 0 & 0\end{array}$ & 궝 \\
\hline$\$$ & 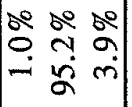 & 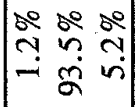 & $\mid \begin{array}{ccc}\therefore 0 & 0 & 5 \\
0 & + & 0 \\
0 & 8 & 0\end{array}$ & 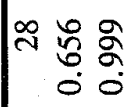 \\
\hline+ & $\left|\begin{array}{ccc}0 & 0 & 20 \\
\hdashline & \infty & m \\
- & 0 & -1\end{array}\right|$ & $\left|\begin{array}{lll}\text { se } & \text { se } & \text { se } \\
0 & y & 0 \\
m & d & \text { di }\end{array}\right|$ & 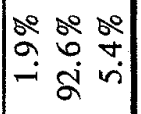 & 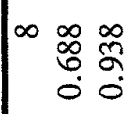 \\
\hline$\sum$ & $\left|\begin{array}{ccc}0 & 20 & \text { å } \\
0 & -1 & 9 \\
0 & 2 & -1\end{array}\right|$ & $\left|\begin{array}{ccc}0 & 50 & 50 \\
0 & n & n \\
0 & 5 & i \\
0 & 5 & 1\end{array}\right|$ & 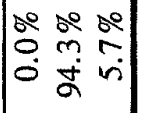 & 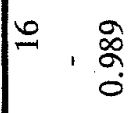 \\
\hline Q & 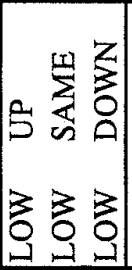 & 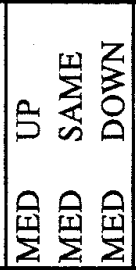 & 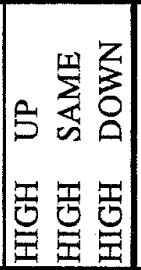 & 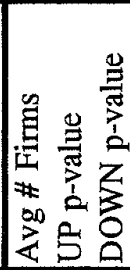 \\
\hline
\end{tabular}

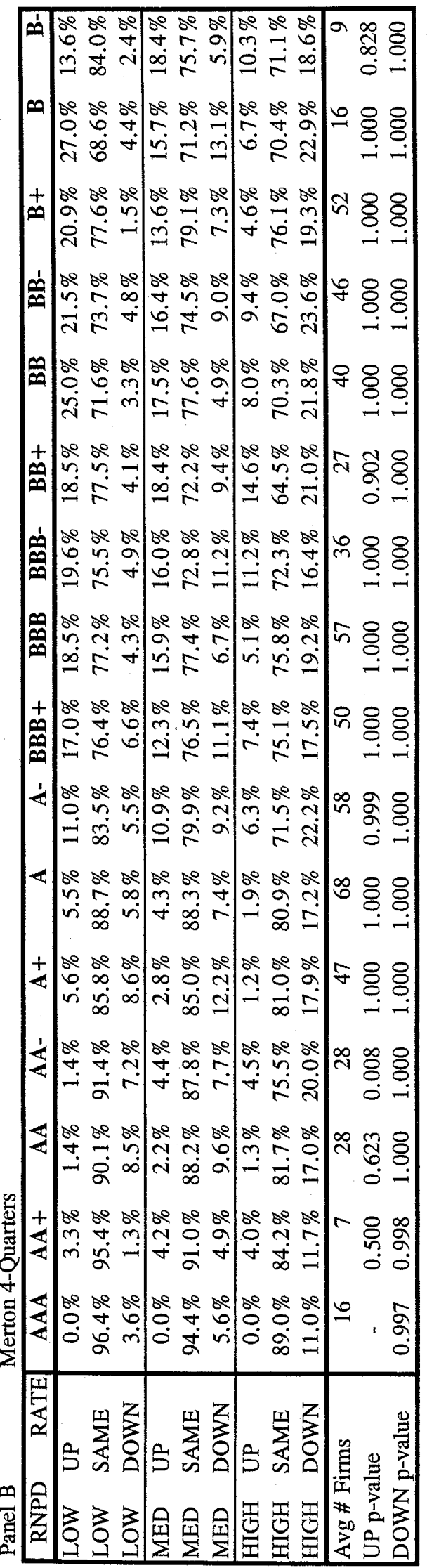




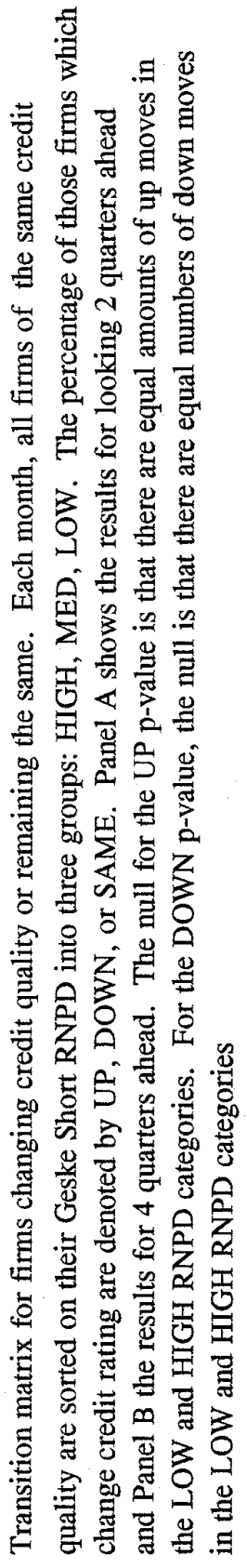

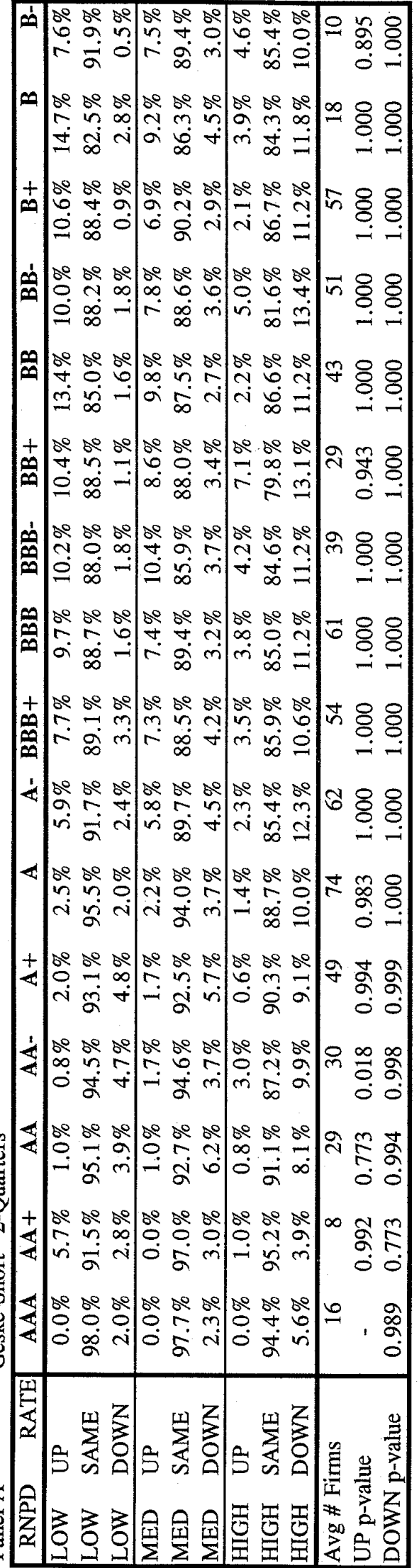

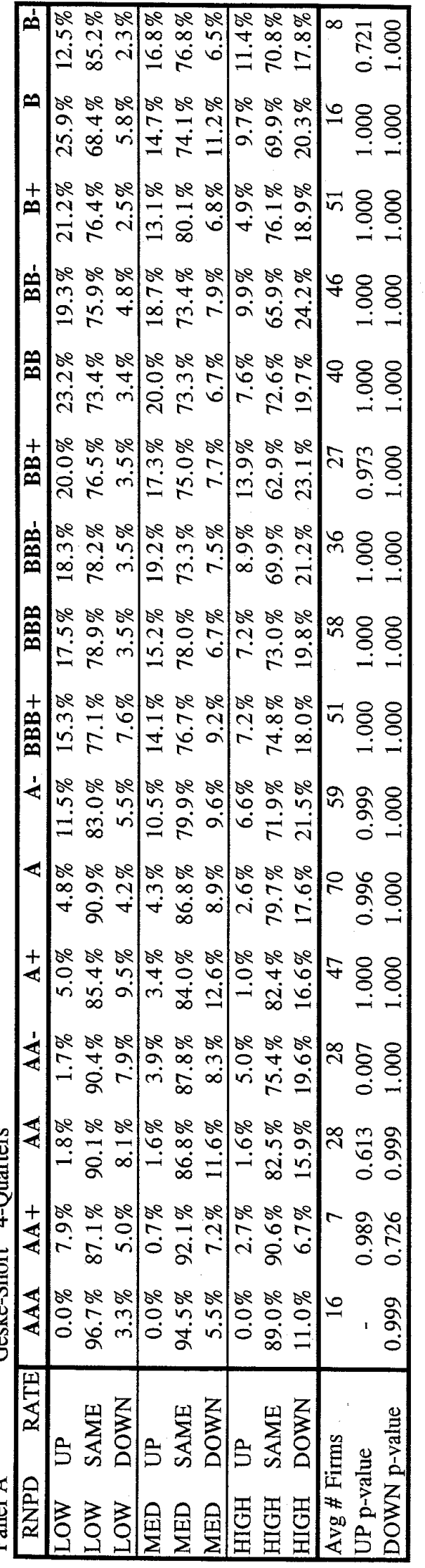




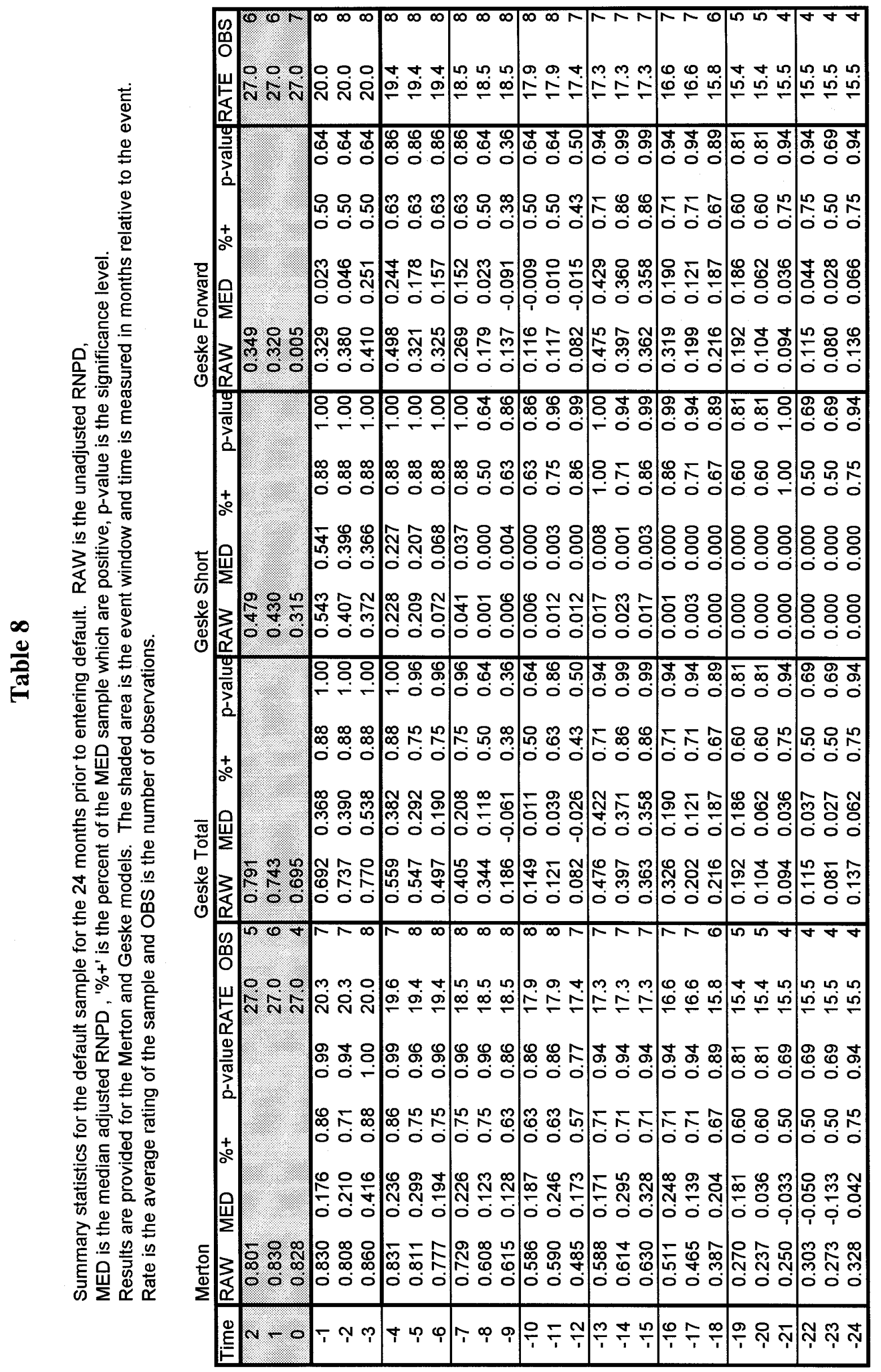

